\title{
Can shorter transfer chains and transparency reduce embezzlement?
}

\author{
Salvatore Di Falco ${ }^{\mathrm{a}}$, Brice Magdalou ${ }^{\mathrm{b}}$, David Masclet ${ }^{\mathrm{c}}$, \\ Marie Claire Villeval ${ }^{\mathrm{d}}$, Marc Willinger ${ }^{\mathrm{b}}$
}

\begin{abstract}
We study embezzlement when donations have to pass through intermediaries to reach recipients, by means of a sequential game tested in a laboratory experiment conducted in Tanzania. We investigate the impact on the amount embezzled of both the number of intermediaries in transfer chains and transparency about the donation. We show that donors are less generous in the presence of intermediaries. When transfer chains are shorter, aggregate embezzlement decreases, at least when donations are transparent. At the individual level, intermediaries embezzle less, the longer the transfer chain; this is due to less embezzlement at the beginning of the chain. We fail finding significant positive effects of transparency on the honesty of individual transfers through social judgment.
\end{abstract}

JEL Codes: C91, D73, O19

Keywords: Embezzlement, corruption, donations, transparency, experiment

a University of Geneva, Bd du Pont-d'Arve 40, CH-1211 Genève 4, Suisse; Email: salvatore.difalco@unige.ch

${ }^{b}$ University of Montpellier, CEE-M, avenue Raymond Dugrand - Site Richter C.S. 79606, F34960 Montpellier Cedex 2, France. E-mail: brice.magdalou@umontpellier.fr, marc.willinger@umontpellier.fr

${ }^{\mathrm{c}}$ University of Rennes, CREM, 7 place Hoche, 35000 Rennes, France, and CIRANO, Montreal. E-mail: david.masclet@univ-rennes1.fr

dUniv Lyon, CNRS, GATE UMR 5824, 93, Chemin des Mouilles, Ecully, F-69130, France; IZA, Bonn. E-mail: villeval@gate.cnrs.fr

Acknowledgments: We are grateful to the Editor, two reviewers, A. Angelsen, G. Attanasi, A. Barr, E. Bulte, L. Butera, G. Charness, M. Dufwenberg, C. Fluet, U. Gneezy, J. Hella, D. Houser, R. Lokina, T. Palfrey and participants at seminars at BETA Strasbourg, European University Institute in Florence, GATE Lyon, the HOME General Directorate at the European Commission in Brussels, ICES at George Mason University, Laval University in Quebec, London School of Economics, Oxford University, University of Maastricht, Wageningen University, and at the IMEBESS conference in Toulouse, the ASFEE conference in Paris, the ESA world meeting in Sydney, the SPI conference at the University of Chicago, and the workshop in behavioral economics at the University of California at Santa Barbara for useful comments. Financial support from the FELIS program of the French National Agency for Research (ANR-14-CE28-0010-01) is gratefully acknowledged. This research was performed within the framework of the LABEX CORTEX (ANR-11-LABX-0042) of Universite de Lyon, within the program Investissements d'Avenir (ANR-11-IDEX-007) operated by the French National Research Agency (ANR). 


\section{Introduction}

Embezzlement is a major form of corruption besides bribing and extortion. It corresponds to a dishonest act, committed by individuals who misappropriate assets that were entrusted to them in order to monopolize or to steal them. ${ }^{1}$ Press releases regularly illustrate embezzlement by politicians, artists, or even ecclesiastics. Embezzlement is a pervasive activity in many domains, including charities, remittances and international aid. It is also a worldwide problem that is particularly worrying in developing countries because it generates inefficiency and unfairness (Bardhan, 1997; Fantaye, 2004; Fan et al., 2010; Olken and Pande, 2011). ${ }^{2}$ In 2013, the African Development Bank reported that during a 30-year time span embezzlement represents about US\$1.2 trillion in real terms. It is a severe concern for charitable giving, in particular. Donors need to rely on intermediaries to distribute funds to recipients or to undertake development programs. This creates a favorable context for embezzlement, notably because beneficiaries usually ignore the amount of initial donations. This raises an issue both for the organization of the transfer chain and for transparency.

Despite its importance, compared to the large literature on bribing, ${ }^{3}$ embezzlement has received less attention until relatively recently (Reinikka and Svensson, 2004; Olken 2006; Imbert and Papp, 2011; Niehaus and Sukhtankar, 2013; Dreze and Khera, 2015; Muralidharan et al., 2016; Banerjee et al., 2018, 2019; Attanasi et al., 2019). A major difference between

\footnotetext{
${ }^{1}$ Embezzlement can use several techniques such as falsification of records, emission of false bills, declaration of ghost employees or stealing money in cash. In political science, Green (1993) defines embezzlement as a "theftafter-trust offense".

${ }^{2}$ For instance, under the reign of Mubutu (DR Congo) theft of overseas aid money or resource rents was estimated over US\$ 4 billion. US\$1.8 million given to Sierra Leone by the Department for International Development to support peacekeeping disappeared. Uganda spent $20 \%$ of its public expenditures on education in the mid 90 s but schools received only $13 \%$ of the government spending on the program; $20 \%$ of teachers' salaries in 1993 paid to ghosts (Reinikka and Svensson, 2004). After the 2010 earthquake the charity Yele Haiti gathered over US\$16 million in donations, but less than $1 / 3$ was distributed to emergency relief for Haitians.

${ }^{3}$ See e.g., Rose-Ackerman, 1975; Shleifer and Vishny, 1993; Abbink et al., 2002; Bertrand et al., 2007; Olken, 2007; Cameron et al., 2009; Barr and Serra, 2010; Vicente, 2010; Armantier and Boly, 2011, 2012; Abbink and Serra, 2012; Banerjee et al., 2012; Serra and Wantchekon, 2012; Banuri and Eckel, 2015; Gneezy et al., 2015; Sequeira, 2016; Dimant and Tosato, 2018).
} 
embezzlement and bribing is that bribing always involves joint dishonesty between several players, which is not necessarily the case with embezzlement.

This paper considers a situation where donors have to use intermediaries to transfer a donation to recipients. ${ }^{4}$ We study experimentally the embezzlement of senders' donations by intermediaries and its consequences on recipients' welfare. In real settings, two dimensions in particular can affect the distribution of donations. One is relative to the number of intermediaries between a donor and the final recipient. Another one is relative to the lack of transparency of intermediaries' actions because monitoring is difficult, especially in the domain of international aid. This is why increasing transparency has been on the agenda of organizations and governments for decades. ${ }^{5}$ We address the following questions: (i) How is embezzlement influenced by the length of the transfer chain between donors and recipients? (ii) To what extent can making the donors' generosity transparent to the recipients reduce embezzlement, by making it more visible? And (iii) is the impact of transparency conditional on the length of the transfer chain? Adding more links increases both the number of intermediaries in a position to steal and the opportunity to dismiss suspicions of fraud onto other links. Thus, increasing transparency may not be so effective in longer transfer chains.

In this domain, collecting reliable data from the field is difficult because it is a secretive activity. Laboratory experiments are highly stylized, but reassuringly, several studies have shown the external validity of corruption experiments (e.g., Armantier and Boly, 2012) and cheating experiments (List, 2009; Hanna and Wang, 2015; Cohn et al., 2015; Gächter and Schultz, 2016; Dai et al., 2018). They show that lab experiments are able to capture moral concerns that govern

\footnotetext{
${ }^{4}$ This mimics real world situations like, for example, that of a rich country sending resources for implementing development projects in a poor country. The resources have to be managed by local actors at several levels.

${ }^{5}$ Since recently donors can find more easily information about charities' efficiency thanks to on-line providers of comparative information such as Charity Navigator or Charity Watch. But there is no clear evidence about the degree of efficacy and integrity at each level of intervention, especially in countries with weaker civic values. Moreover, beneficiaries of aid are usually not well informed about the initial aid: for example, in their study on embezzlement in Uganda schools Reinikka and Svensson (2004) show that part of the problem is the exploitation by local officials of the very limited knowledge of the parents about the public grants to which they were entitled.
} 
(un)ethical behavior. Thus, we believe that our experiment is useful to identify causal relationships between the exogenous manipulation of the transfer chain and of information and intermediation behavior.

Our experiment consists of five treatments. The baseline treatment is a standard dictator game. The four other treatments, played between-subjects, recruit a sequential game. A sender, $\mathrm{A}$, can make a transfer to a recipient, $\mathrm{C}$, like in a dictator game. But the transfer cannot be carried out directly: it requires passing through intermediaries, B. ${ }^{6}$ Along one dimension, we vary the number of intermediaries (one or two) to investigate how the length of the transfer chain affects intermediaries' behavior and recipients' welfare. Along the other dimension, we manipulate information by letting the recipient know the amount of the original donation, and therefore infer embezzlement by intermediaries. We test whether such minimal transparency is able to lower embezzlement when there is no associated risk of sanction. This could be the case if intermediaries' exhibit perceived cheating aversion (Dufwenberg and Dufwenberg, 2018; Gneezy et al. 2018; Abeler et al., 2019). We predict that embezzlement should be reduced by transparency, but less effectively so in long chains because of a reduced perceived cheating aversion due to diluted responsibilities.

Our experiment was conducted with students in two university campuses located in Dar-esSalaam and Mazimbu in Tanzania. Tanzania ranks 119 out of 175 countries in the corruption perception index and it scores 31 out of 100 (from 0 for very corrupted to 100 for very clean) (Transparency International, 2014). ${ }^{7}$ By involving subjects from a country in which the empirical norm of embezzlement is relatively low, we expect to observe the phenomenon more easily,

\footnotetext{
${ }^{6}$ Compared to the standard dictator game (Forsythe et al., 1994; Hoffman et al., 1994) one can find very few sequential dictator games in the literature. For example, in Bahr and Requate (2007) a player A divides a pie between himself and a player B who can then divide the rest with player C. Our game is very different: player A decides on how to share his endowment with player C, while the role of player B is exclusively to transfer this amount from A to $\mathrm{C}$. While formally $\mathrm{B}$ is in the position to share the amount received between him and the next player, it is made clear in the instructions that $\mathrm{A}$ wants $\mathrm{B}$ to transfer his donation to $\mathrm{C}$.

${ }^{7}$ On corruption scandals in Tanzania, see Gray (2015). For example, an Ernst and Young's report mentions that in 2013 US\$1.3 million disappeared from a Norwegian funded WWF project, "Strengthening Capacity of Environmental Civil Society Organizations".
} 
such that we can study the efficacy of our treatment manipulations. However, we expect that our results would replicate in other places with weak empirical norms.

We found that senders are less generous in the presence of intermediaries; longer transfer chains reduce donations when they are transparent; otherwise, donations are not affected by transparency. The mean percentage of the initial donation that is embezzled varies from $50.55 \%$ to $74.88 \%$ across treatments. Only $24 \%$ to $40.48 \%$ of the intermediaries transfer to the next player the whole donation received. With longer chains aggregate embezzlement increases. However, at the individual level the mean percentage of transfers that is embezzled by an intermediary is smaller than in short chains. This effect is driven by the intermediaries who intervene earlier in the chain and who seem to express concern for the recipient or for the next intermediary in the chain. Transparency decreases the percentage of the transfer that is embezzled, but this is observed only in short transfer chains and without reaching a standard significance level.

The remainder of the paper is organized as follows. Section 2 reviews briefly the related literature. Section 3 describes our experimental strategy and introduces our main hypotheses. Section 4 analyzes the results. Section 5 discusses these results and concludes.

\section{Literature Review}

Our paper contributes to four strands of literature. First, it contributes to the scarce literature on the mechanisms designed to reduce embezzlement. In an experimental study on service delivery in Ethiopia, Barr et al. (2009) found less embezzlement when intermediaries' wages or the monitoring probability were higher, and when monitors were elected rather than randomly chosen. A novelty of our paper is to consider alternative interventions, such as shortening the transfer chain and allowing minimal transparency to vehicle social judgment. Makowski and Wang (2015) also investigate the impact of the number of layers on embezzlement but they use a common pool resource game, assuming that withdrawals can represent a dishonest action. 
Second, our paper contributes to the existing literature on the determinants of (un)ethical behavior in presence of intermediation. In moral decision-making, studies have shown that intermediation alleviates perceived responsibility (e.g., Fershtman and Gneezy, 2001; Bartling and Fichbacher, 2012) and guilt (e.g., Hamman et al., 2010), and weakens pro-social norms; for example, when charitable donations have to pass through an intermediary punishment of selfish actions is less likely (Coffman, 2011). In the domain of corruption, Drugov et al. (2014) have found that by facilitating the relationship between a briber and a bribee, intermediaries intensify corruption by lowering its moral cost (see also Hasker and Okten, 2008). ${ }^{8}$ Using psychological game theory and a model with belief-dependent preferences, Attanasi et al. (2019) show, however, that guilt aversion toward either the donor or the recipient reduces embezzlement by intermediaries. This suggests that the feeling of guilt comes from the betrayal of others' intentions as much as from the monetary consequences of one's actions.

Also, comparing charitable giving with and without intermediaries using a within-subject design, Chlaß et al. (2015) have shown that most donors are either price-oriented (i.e., they donate less in the presence of intermediaries because embezzlement raises the implicit price of giving) or donation-oriented (i.e., they donate the same amount with intermediaries than without), rather than outcome-oriented (i.e., they increase their donation to compensate for expected embezzlement). Finally, Beekman et al. (2014) found that when local chiefs embezzle more resources, villagers are less likely to contribute to local public goods. In contrast to these previous studies, our main focus is on the intermediaries' behavior rather than on the donors' or recipients' behavior, and we manipulate both the length of the transfer chain and information. ${ }^{9}$

Third, we contribute to the expanding literature on the relationships between transparency and the performance of institutions (e.g., Azfar and Nelson, 2007; Olken, 2007; Kolstad and

\footnotetext{
${ }^{8}$ On the other hand, modeling embezzlement as a substitute for efficiency wages, Fan et al. (2010) sustain that tolerating embezzlement helps better fight bribery.

${ }^{9}$ Banerjee et al. (2015) also propose a game of embezzlement but their game is based on misreporting. They study whether embezzlement is higher for public sector aspirants than private sector applicants.
} 
Wiig, 2009; Reinnikka and Svensson, 2004, 2011). Azfar and Nelson (2007) have shown that corruption is lower when hiding corrupt gains is more difficult. Using a joy-of-destruction game, Abbink and Herrmann (2011) found that people behave more nastily when they can hide behind a random device. However, the previous literature has also shown that transparency is not always effective. This is the case when behavior is not perceived as reprehensible (de Vries and Sobis, 2016) or when transparency institutions are implemented by the agent himself (Lindstedt and Naurin, 2010). While Olken (2006) found a positive effect of local monitoring, Platteau (2004) or Abbink and Ellmann (2010) have shown that transparency has little effect when intermediaries select the beneficiaries of aid. Indeed, potential recipients may withhold complaints against dishonest intermediaries to avoid not being selected. ${ }^{10}$

Our paper explores whether making donations, and therefore embezzlement, more transparent to recipients can discourage unethical behavior and whether a mediator is the length of the transfer chain. In contrast to most studies mentioned above, in our design intermediaries cannot choose among recipients and they incur no risk of sanctions. Instead, we focus on whether transparency activates social judgment as an enforcement mechanism. In that sense, we are closer to Salmon and Serra (2017) who found that social judgment reduces corruption for people in the U.S. who identify with a culture of low corruption.

The last strand of related literature is on how uncertainty affects pro-social behavior in dictator games. Uncertainty is usually considered either on the side of the sender (Dana et al., 2007; Winschel and Zahn, 2014) or on the side of the receiver (Rapoport and Sundali, 1996; Huck, 1999; Güth et al., 1996). Introducing intermediaries and manipulating information allow us to consider the impact of uncertainty on both sides in the same study.

\footnotetext{
${ }^{10}$ Using a three-player trust game in a different context (intermediation in financial markets), Rietz et al. (2013) found that transparency of the exchanges between investors and intermediaries has no impact, whereas the transparency of the exchanges between intermediaries and borrowers increases investors' trust.
} 


\section{Experimental Design and Procedures}

In this section, we present our experimental design, then the procedures, and finally, our main hypotheses.

\subsection{Experimental Design}

Our experiment consists of a baseline condition using a dictator game without intermediary and four other treatments in which we manipulate both the number of intermediaries and information. Each treatment is identified as \#-Int-T, where \# $=\{0,1,2\}$ is the number of intermediaries and $T=\{I, N I\}$ accounts for transparency. All treatments implement a one-shot zero-sum game (i.e., with no possibility of retaliation), using a between-subject design. This has several advantages. First, by playing the game only once we are able to capture pure treatment effects regarding the length of the chain and transparency. Repeating the game could have affected subjects' beliefs about future interactions and transformed the nature of strategic interactions. Using a one-shot design was also motivated by logistic considerations and the willingness to minimize mistakes during the procedure of physical transfer of the money across types of players, as detailed below. Second, a within-subject design would have required to control for the sequence of treatments, because behavior in future interactions may be conditioned on the outcome of past interactions. Let us describe first the baseline.

The baseline treatment (0-Int, hereafter) is a dictator game involving a sender and a passive recipient, designated as "person $\mathrm{A}$ " and "person $\mathrm{C}$ " respectively (see instructions in Appendix 1). The sender receives an endowment of 15 bank notes of 1000 Tanzanian Shillings (TS), each, and the recipient receives TS2000. ${ }^{11}$ The sender has to decide how many notes to donate to the recipient, between 0 and 15 , inclusive.

In the four other treatments, we introduce sequentiality in the game by placing intermediaries between senders and recipients. Senders are forced to use intermediaries. Our aim is to test to

\footnotetext{
${ }^{11}$ In Tanzania, the average wage in the private sector is TS78000 per month - about US\$45.
} 
which extent the length of the transfer chain affects the share of the donation that is embezzled. The intermediary is designated as "person B" and in case of multiple intermediaries as "person B1" or "person B2", depending on the order in the chain. Each intermediary receives an endowment of TS5000 to keep. ${ }^{12}$ In the 1-Int-NI treatment, the sender's donation transits through a single intermediary; in the 2-Int-NI treatment, it transits through two consecutive intermediaries. Intermediaries are not allowed to transfer a fraction of their own endowment to the recipient. It is crucial that players understand that intermediaries do not play a second dictator game with the next player, and that not transferring the totality of the sender's donation is unethical, as it violates A's intentions. ${ }^{13}$ In the instructions, the intermediaries are told that their role is "to transfer the money to person C". By indicating that the envelope contains the TS "that the person A you are matched with wants you to transfer to person $C^{\prime \prime}$, it is made clear to the subjects that not transferring all the money to the next player is betraying A's intentions. Therefore, while formally B is in the position to share the amount received between him and the next player, it is made clear that A wants $\mathrm{B}$ to transfer his donation to $\mathrm{C}$, and that his role is to transfer the amount received. ${ }^{14}$

In the 1-Int-NI and 2-Int-NI treatments, the sender does not know the amount actually received by the recipient; the second intermediary is not informed on the amount received by the first intermediary, to avoid peer effects on the decision to embezzle; and the recipient ignores how much money was initially sent to him. In contrast, in the 1-Int-I and 2-Int-I treatments the

\footnotetext{
${ }^{12}$ These role-based endowments capture a feature from real settings in which typically donors are from developed countries while intermediaries are located in poorer, developing countries. We acknowledge that senders with distributional preferences might wish to transfer some money to the intermediary. However, the instructions made clear that donations were intended for the recipients. Moreover, using a three-player embezzlement game, Attanasi et al. (2019) elicit the donors' moral norms and show that a majority of them consider that it is not socially appropriate for an intermediary to keep a fraction of the donation for himself. We are confident that in our design too, donors consider that intermediaries keeping money instead of transferring it act unethically.

${ }^{13}$ This is a key reason why donations had to be made by real subjects instead of being imposed by a computer program. It was important to put intermediaries in a situation in which behaving unethically hurts others, both by betraying the donor and by reducing help to the recipient. Identifying whether embezzlers feel more guilt toward the donor or toward the recipient is not the aim of this study but is investigated in Attanasi et al. (2019).

${ }^{14} \mathrm{We}$ did not introduce any risk of detection by a formal authority. This choice is motivated by our interest for the purely intrinsic moral cost associated with embezzlement. In that, we follow the recent developments in the economic analysis of lying behavior using random devices (see Abeler et al., 2019, for a meta-analysis).
} 
recipient learns the amount of the sender's donation and this is made common knowledge to all players. Note that in the 2-Int-I treatment, individual embezzlement is not directly observable, neither by the recipient nor by the intermediaries (in particular, the second intermediary does not know how much money was embezzled by the first intermediary).

By comparing these treatments with and without information, our aim is to test whether social judgment through making the recipient aware of the total amount embezzled can reduce embezzlement by increasing its moral cost. Our notion of transparency is minimal but this form of scrutiny might be sufficient to create a moral pressure on intermediaries, as the literature on lying has shown that even mild forms of scrutiny reduce lying. ${ }^{15}$ By manipulating both the number of intermediaries and information, we can test whether the impact of the transparency of information on embezzlement depends on the size of the transfer chain.

A brief questionnaire concluded the experiment. Filling out this questionnaire paid TS2000 for sure plus an additional TS2000, depending on the reported outcome of a coin toss made in private, like in Bucciol and Piovesan (2011) or Abeler et al. (2014). Subjects were instructed to toss the coin that was put on their table as many times as they wanted but they were asked to report only the outcome of the first toss. Reporting heads paid TS2000, reporting tails paid nothing. The aim of this task was to give us a simple measure of unethical behavior at the aggregate level in our sample of subjects when social preferences do not come into play.

\subsection{Procedures}

The experiment was conducted in Tanzania on the campuses of the University of Dar-es-Salaam and Sokoine University of Agriculture in Mazimbu. These are the two biggest universities in the country, providing education on a wide range of subjects (including science, agriculture, business, planning). The aim was both to limit the dissemination of information about the content

\footnotetext{
${ }^{15}$ For example, compared to the die-under-the-cup paradigm in which the experimenter cannot know the truth (Shalvi et al., 2011; Fischbacher and Föllmi-Heusi, 2013), subjects lie less when the experimenter can identify a lie at the individual level after they have left the laboratory (Kajackaite and Gneezy, 2017).
} 
of the experiment and to diversify the origin of the subjects, one university being located in the country's largest city and the other one in a rural area. The choice of Tanzania was motivated by the high rate of corruption in the country. Consistently, our coin flip task indicates widespread cheating: $91.02 \%$ of the subjects reported heads, which differs significantly from $50 \%$ (binomial test: $p<0.001$ ). In comparison, in Houser et al. (2012) $74.5 \%$ of the subjects reported the wining outcome in a coin flip task played after a dictator game. This suggests a low level of ethics in our pool of subjects. ${ }^{16}$

1080 students were recruited (540 on each campus) via announcements on the bulletin board system and in teaching buildings. Each of our ten sessions involved between 90 and 120 subjects, depending on the treatment. The intention with having only two but large sessions by treatment was again to limit the dissemination of information about the content of the experiment across sessions. Table 1 provides summary statistics for the sessions and the subjects' main characteristics. The null hypothesis of equal characteristics across locations is rejected for several variables. It is thus crucial to control for these variables in our analysis.

Table 1. Comparison of the two subject pools

\begin{tabular}{llll}
\hline Location & Dar-es-Salaam & Mazimbu & Total \\
\hline Characteristics of the sessions & & & \\
Treatments & Nb subjects & Nb subjects & Nb subjects (Nb groups) \\
0-Int & 120 & 120 & $240(120)$ \\
1-Int-NI & 90 & 90 & $180(60)$ \\
1-Int-I & 90 & 90 & $180(60)$ \\
2-Int-NI & 120 & 120 & $240(60)$ \\
2-Int-I & 120 & 120 & $240(60)$ \\
Total & 540 & 540 & $1080(360)$ \\
\hline Characteristics of the subjects & & & $p$-values \\
Male & $65.65 \%$ & $75.55 \%$ & $<0.001^{\mathrm{a}}$ \\
Age & $22.27(2.37)$ & $22.89(3.21)$ & $0.003^{\mathrm{b}}$ \\
Married & $4.27 \%$ & $8.16 \%$ & $0.001^{\mathrm{a}}$ \\
Christian & $83.15 \%$ & $83.30 \%$ & $0.946^{\mathrm{a}}$ \\
Muslim & $15 \%$ & $15.40 \%$ & $0.855^{\mathrm{a}}$ \\
Religious practice (1 to 5) & $4.09(1.05)$ & $4.15(1.03)$ & $0.416^{\mathrm{b}}$ \\
Low family wealth & $15.93 \%$ & $27.59 \%$ & $<0.001^{\mathrm{b}}$ \\
\hline
\end{tabular}

Notes: ${ }^{\mathrm{a}}$ indicates proportion tests and ${ }^{\mathrm{b}}$ Mann-Whitney tests in which one subject gives one independent observation. Religious practice is coded 1 for "never pray", 2 for "pray rarely", 3 for "pray every week", 4 for "pray once per

\footnotetext{
16 Due to the high proportion of subjects reporting the high outcome in the coin task, we cannot correlate this behavior with the decisions in the embezzlement game. If intermediaries report significantly more frequently heads than senders (proportion test: $p=0.093$ ), no other pairwise comparison indicates significant differences.
} 
day", and 5 for "pray several times per day". Family wealth is assessed through the answer to the question: "If you compare your family's economic conditions to the others in your hometown, your family is: very poor / poor / average / rich / very rich." "Low family wealth" is equal to 1 if the response is "very poor" and "poor" and 0 otherwise.

Upon arrival, subjects were seated in a large aula and received the instructions for all roles in both Swahili and English, such that all the details about roles and payoffs were common knowledge. The instructions were read aloud. A short quiz was then distributed to ensure that the tasks were fully understood. Next, the correct answers were written on the blackboard. Subjects had the possibility to ask questions in privacy. Then, subjects were split randomly into 2,3 or 4 separate and isolated rooms, depending on the treatment, with each room corresponding to a different role. We instructed subjects not to talk with anyone while proceeding to their room and this was strictly enforced. In each room, several seats isolated each subject from his neighbors in order to avoid communication and scrutiny (see Appendix 2). Once all the subjects were seated, they discovered which role was assigned to them. Then, they were given some time to read again the instructions. Each subject received a random group identification number matching persons $\mathrm{A}, \mathrm{B}$ and $\mathrm{C}$.

To avoid scrutiny, we used large opaque bags to transfer the money and for the subjects to make their decision secretly (see Appendix 2). Each sender received a bag containing two envelopes: a white envelope containing 15 notes of TS1000 and a brown envelope that was empty. The brown envelope could be used to send money to the recipient and it had to be kept in the bag. The senders had to decide how many notes to move from the white to the brown envelope. Subjects were instructed to make their transfer -if any- within the bag so that their decision could not be observed by anyone. Then, assistants collected the bags and brought them to a separate room where the content of the brown envelope was recorded under the supervision of the experimentalist. Then, assistants distributed the bags containing both the brown envelope to the recipients in treatment 0 -Int or to each matching intermediary in the other treatments, and a white envelope containing the endowment of the next player (five notes for an intermediary or 
two for the recipient). The intermediaries were instructed to count the content of their white and their brown envelopes within the bag and to take out the white envelope for them to keep. At this precise moment, they had an opportunity to move notes from the brown envelope containing the donation to their white envelope. They were also told that they could not put their own notes in the brown envelope. A similar procedure was implemented in the case of two intermediaries. Finally, after assistants had collected the bags, the content of the brown envelopes was again recorded in a separate room. ${ }^{17}$ After adding a new white envelope to the brown envelope, the bags were brought to the recipients' room.

Once the bags were collected, we administered the final questionnaire. In contrast to the other players, the recipients filled out their questionnaire before receiving their bag since they had nothing to do than wait for others' decisions. Then, subjects had to report the toss of the coin to determine additional payment. We were careful to dismiss the subjects in the different rooms at different moments so that they could not meet each other and try to identify their matching partners. This is why the length of the experiment ranged from 30 to 90 minutes depending on the treatment and the role. Earnings averaged at TS11330.

\subsection{Conjectures}

Under the assumption of standard selfish preferences, our theoretical predictions are straightforward. In all treatments the sender will always keep the whole amount received for himself and therefore, there is nothing to embezzle. However, if players have social preferences or moral concerns, senders and intermediaries are both likely to transfer some money to the receiver. We rely on two different models to guide our conjectures: inequality aversion (Fehr and Schmidt, 1999) and guilt aversion (Battigalli and Dufwenberg, 2007).

\footnotetext{
${ }^{17}$ We did not use a double-blind procedure; thus, subjects may have anticipated that their decision was recorded. Note that we are not interested in making point predictions about the extent of embezzlement in real settings. We are interested in treatment effects.
} 
Let us consider first the effect of inequality aversion. Senders are expected to transfer some money to the receiver if they exhibit advantageous inequality aversion. Intermediaries are expected to embezzle some of the money transferred by the sender if their disadvantageous inequality aversion (toward the donor) is stronger than their advantageous inequality aversion (toward the recipient), which is a common assumption. This model predicts any level of embezzlement between $0 \%$ and $100 \%$, depending on the relative magnitudes of the advantageous and disadvantageous inequality aversion parameters. ${ }^{18}$ For a given amount donated by the sender, increasing the number of inequality averse intermediaries is likely to increase the total amount embezzled at the aggregate level. At the individual level, it should not change behavior compared to a short chain regardless of the first intermediary's beliefs about the other intermediary's behavior. The inequality aversion model predicts no effect of transparency in our context on the amounts transferred and embezzled.

Let us now consider the effect of guilt aversion. Battigalli and Dufwenberg (2007) have introduced two concepts of guilt aversion in psychological game theory: simple guilt and guilt from blame. Simple guilt captures how much a player with belief-dependent preferences and guilt sensitivity cares about the extent to which he lets another player down (i.e., he disappoints the expectations of another player). If players are guilt sensitive and believe that the other player expects a positive transfer, we conjecture that both senders and intermediaries will make a positive transfer. ${ }^{19}$ This mechanism can be activated in players regardless of whether donations are transparent or not, and independently of the length of the transfer chain.

\footnotetext{
${ }^{18}$ If the parameters of disadvantageous and advantageous inequality aversion are the same, inequality aversion should have no effect on embezzlement. Indeed, embezzling would reduce inequality between the intermediary and the sender but it would also increase inequality to the same extent between the intermediary and the receiver, with no positive net effect in terms of moral utility.

${ }^{19}$ Attanasi et al. (2019)'s model shows that guilt aversion toward the donor and toward the recipient should have the same impact on embezzlement, although the donor's payoff is not affected by it. Their data confirms the model.
} 
In contrast to simple guilt, guilt from blame captures a player's expectation about the extent of the blame of the player whom he let down. Guilt from blame is affected both by transparency and by the length of the chain. In the absence of transparency, intermediaries know that the receiver cannot target his blame towards a single agent. Therefore, we expect guilt from blame to play a minor role (or no role) in the absence of transparency. Under transparency, in short chains both the sender and the intermediary can be targeted to be blamed by the recipient. If players are sensitive to guilt from blame, we expect senders to increase their transfer and single intermediaries to reduce embezzlement. In longer chains, intermediaries cannot be individually targeted for blame, which should increase individual embezzlement in long chains compared to short chains. Therefore, transparency should decrease embezzlement only in short chains.

We derive four conjectures from this analysis. ${ }^{20}$ The first three conjectures are supported by both inequality aversion and simple guilt aversion models. The fourth conjecture is supported only by guilt from blame aversion.

Conjecture 1: Senders donate a strictly positive amount to the recipient and intermediaries transfer a strictly positive share of the amount received to the next player.

Conjecture 2: At the aggregate level, embezzlement increases as the number of intermediaries increases.

Conjecture 3: At the individual level, in the absence of transparency and for a given amount donated by the sender, an increase in the number of intermediaries does not affect embezzlement.

Conjecture 4: In short transfer chains, transparency reduces embezzlement. In long transfer chains, transparency cannot reduce embezzlement.

\section{Results}

We start by comparing donations under the various transfer regimes. Then, we analyze the impact of the transfer chain length and that of transparency on embezzlement. We conclude with the recipient's actual earnings.

\footnotetext{
${ }^{20}$ Note that we only present conjectures, as our data does not allow us to test these models directly since it would have been too complex and time consuming to collect data on the players' first and second order beliefs and their degree of inequality aversion.
} 


\subsection{Senders' Donations}

Table 2 provides summary statistics on the senders' donations and earnings, by treatment. It confirms Conjecture 1 for the senders: the percentage of senders making a donation is positive in all treatments. It is $91.67 \%$ in the 0 -Int treatment and it decreases significantly according to proportion tests when intermediaries are introduced $(75 \%, p<0.001$ in short chains; $83.33 \%$, $p=0.051$ in long chains). Senders become less generous when the chain is long: while donations represent on average $25.61 \%$ of the endowment in 0 -Int, this percentage decreases to $22.83 \%$ in the short chain treatments (Mann-Whitney tests ${ }^{21}-\mathrm{MW}$ hereafter-, $p=0.123$ ) and to $18.17 \%$ in the long chain treatments $(p<0.001)$. This is not consistent with predictions based on inequality aversion or guilt aversion theories. But this is consistent with the results of Chlaß et al. (2015), suggesting that senders are price-oriented: they donate less when more TS have to be donated for one TS to reach the receiver. Table 2 indicates that transparency does not affect donations significantly. The mean percentage sent is $22.33 \%$ in 1 -Int-NI and $23.33 \%$ in 1 -Int-I ( $p=0.437)$, $21.11 \%$ in 2 -Int-NI and $15.22 \%$ in 2 -Int-I $(p=0.207)$.

Table 2. Summary statistics - Senders

\begin{tabular}{lccccc}
\hline Treatments & 0-Int & 1-Int-NI & 1-Int-I & 2-Int-NI & 2-Int-I \\
\hline Nb of donations $>0 /$ total & $110 / 120$ & $50 / 60$ & $40 / 60$ & $49 / 60$ & $51 / 60$ \\
$(\%)$ & $(91.67)$ & $(83.33)$ & $(66.66)$ & $(81.66)$ & $(85.00)$ \\
Mean amount donated in TS & 3841.67 & 3350 & 3500 & 3166.67 & 2283.33 \\
(if 0 excluded) & $(4190)$ & $(4020)$ & $(5250)$ & $(3877)$ & $(2686)$ \\
Mean percent. donated & 25.61 & 22.33 & 23.33 & 21.11 & 15.22 \\
Mean final earnings in TS & 11158.33 & 11650 & 11500 & 11833.33 & 12716.67 \\
\hline
\end{tabular}

Note: The mean amounts donated include amounts equal to 0 . In parentheses we indicate the mean amount donated when excluding senders who do not donate a positive amount.

To control for a possible influence of individual socio-demographic characteristics, Table 3 reports a regression analysis in which the dependent variable is the amount donated by the sender. We use Tobit models since data are censored both on the left and on the right. In model (1) the independent variables include dummies for short chain, long chain, and transparency. The second

\footnotetext{
${ }^{21}$ In the rest of the section, unless specified otherwise all the non-parametric statistics are based on two-tailed MannWhitney tests in which each subject gives one independent observation.
} 
model includes only the treatments in which donations are transparent to the receiver (0-Int, 1Int-I and 2-Int-I), with the same reference category and the same independent variables, except transparency. The third model includes only the treatments without transparency (1-Int-NI and 2-Int-NI), with the short chain treatment as the reference. Each model controls for the location of the experiment and for several socio-demographic characteristics (gender, age, marital status, Christian religion and intensity of the religious practice). Similar models without sociodemographic variables are reported in Appendix Table A1; their results are qualitatively similar to those of Table 3.

Table 3. Determinants of the amount donated by the Sender

\begin{tabular}{|c|c|c|c|}
\hline $\begin{array}{l}\text { Dep. variable } \\
\text { Amount donated }\end{array}$ & $\begin{array}{l}\text { All } \\
(1)\end{array}$ & $\begin{array}{c}\text { Transparency } \\
\text { (2) }\end{array}$ & $\begin{array}{c}\text { No Transparency } \\
\text { (3) }\end{array}$ \\
\hline No intermediary & Ref. & Ref. & - \\
\hline Short chain & $\begin{array}{c}-657.760 * * \\
(302.76)\end{array}$ & $\begin{array}{l}-552.467 \\
(349.77)\end{array}$ & Ref. \\
\hline Long chain & $\begin{array}{c}-928.718 * * * \\
(289.51)\end{array}$ & $\begin{array}{c}-1020.069 * * * \\
(305.93)\end{array}$ & $\begin{array}{c}18.689 \\
(375.09)\end{array}$ \\
\hline Transparency & $\begin{array}{c}-275.680 \\
(280.45)\end{array}$ & - & - \\
\hline Dar-es-Salaam & $\begin{array}{l}-37.307 \\
(225.69)\end{array}$ & $\begin{array}{l}-191.977 \\
(284.35)\end{array}$ & $\begin{array}{l}290.552 \\
(371.61)\end{array}$ \\
\hline Male & $\begin{array}{l}199.246 \\
(253.86)\end{array}$ & $\begin{array}{l}126.563 \\
(308.69)\end{array}$ & $\begin{array}{l}227.077 \\
(454.59)\end{array}$ \\
\hline Age & $\begin{array}{c}60.246 \\
(46.731)\end{array}$ & $\begin{array}{c}58.703 \\
(62.219)\end{array}$ & $\begin{array}{c}33.857 \\
(72.281)\end{array}$ \\
\hline Married & $\begin{array}{l}222.332 \\
(547.74)\end{array}$ & $\begin{array}{l}101.575 \\
(704.72)\end{array}$ & $\begin{array}{l}798.317 \\
(948.03)\end{array}$ \\
\hline Christian & $\begin{array}{r}-430.710 \\
(338.93)\end{array}$ & $\begin{array}{l}-265.786 \\
(436.07)\end{array}$ & $\begin{array}{r}-600.042 \\
(532.17)\end{array}$ \\
\hline Religious practice & $\begin{array}{c}271.032 * * \\
(110.61)\end{array}$ & $\begin{array}{l}167.373 \\
(144.03)\end{array}$ & $\begin{array}{c}448.072 * * * \\
(173.28)\end{array}$ \\
\hline Number of obs. & 356 & 236 & 120 \\
\hline Left/right censored obs. & $59 / 5$ & $38 / 5$ & $21 / 0$ \\
\hline Log pseudo-likelihood & -2864.678 & -1900.262 & -962.163 \\
\hline Prob $>$ Chi 2 & 0.017 & 0.101 & 0.172 \\
\hline Pseudo $\mathrm{R}^{2}$ & 0.003 & 0.003 & 0.005 \\
\hline
\end{tabular}

Notes: Table 3 reports marginal effects from Tobit models. Standard errors are in parentheses. Left censored observations correspond to a null transfer and right-censored observations to a transfer of the full endowment to the next player. Male, married and Christian are dummy variables. Religious practice is coded from 1 to 5 . Four observations on religious practice are missing (two in 0 -Int, one in 1 -Int-I, and 1 in 2 -Int-I). *** and ** indicate significance at the 0.01 and 0.05 level, respectively.

Model (1) shows that the introduction of intermediaries decreases the amount donated significantly, while transparency has no significant effect. The marginal effect of the long chain 
is higher than the effect of the short chain but not significantly so $(p=0.293)$. Model (2) shows that, when donations are transparent, they are significantly smaller in long chains compared to the 0-Int treatment, whereas they do not differ in short chains. Finally, model (3) detects no difference between short and long chains when donations are not transparent. Overall, the results are not sensitive to the location of the experiment and the donor's individual characteristics, except that more religious senders donate more in models (1) and (3).

These findings can be summarized as follows:

Result 1 (Donations): Senders are less generous in the presence of intermediaries; longer transfer chains reduce donations when they are transparent; otherwise, donations are not affected by transparency.

\subsection{Embezzlement and the Length of the Transfer Chain}

We next focus on the amounts embezzled. We first consider embezzlement at the aggregate level. Figure 1 displays the mean percentage of the donations that is embezzled, conditional on receiving a positive transfer from the previous player, by treatment. It indicates that a longer transfer chain tends to increase embezzlement. The mean total percentage of the amount donated by the senders that is embezzled is $50.55 \%$ in 1 -Int-I, $62.04 \%$ in 1 -Int-NI, $71.76 \%$ in 2 -Int-I and $74.88 \%$ in 2-Int-NI. MW tests indicate that the difference between 1-Int-I and 2-Int-I is highly significant $(p=0.005)$, but not the difference between 1-Int-NI and 2-Int-NI $(p=0.115)$. Thus, Conjecture 2 is only partly supported. Result 2 summarizes this analysis:

Result 2. (Embezzlement, aggregate level): The shorter is the transfer chain, the lower is the overall percentage of the donation embezzled, at least when donations are transparent. 


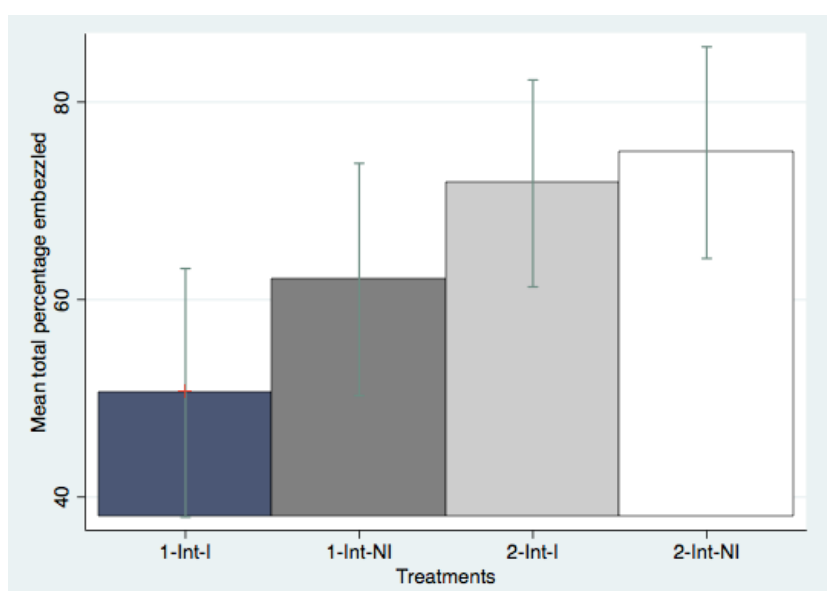

Figure 1. Mean total percentage of the amount donated that is embezzled, by treatment

Next, we consider embezzlement at the individual level. Table 4 summarizes statistics on intermediaries' decisions and earnings.

Table 4. Summary statistics - Intermediaries

\begin{tabular}{|c|c|c|c|c|}
\hline Treatments & 1-Int-NI & 1-Int-I & 2-Int-NI & 2-Int-I \\
\hline Number receiving $>0 /$ total $(\%)$ & $50 / 60(83.33)$ & $40 / 60(66.66)$ & $84 / 120(70)$ & $90 / 120(75)$ \\
\hline -Number transferring $0(\%)$ & $22 / 50(44)$ & $9 / 40(22.5)$ & 28/84 (33.33) & 28/90 (31.11) \\
\hline -Number transferring $>0(\%)$ & $28 / 50(56)$ & $31 / 40(77.5)$ & $56 / 84(66.67)$ & $62 / 90(68.89)$ \\
\hline -Number transferring all (\%) & $12 / 50(24)$ & $12 / 40(30)$ & $34 / 84(40.48)$ & $33 / 90(36.67)$ \\
\hline Mean total percent. embezzled & 62.04 & 50.55 & 74.88 & 71.76 \\
\hline \multicolumn{5}{|l|}{ Intermediary 1} \\
\hline Number receiving $>0 /$ total $(\%)$ & “ & “ & 49/60 (81.67) & $51 / 60(85)$ \\
\hline -Number transferring $0(\%)$ & “ & “ & $14 / 49(28.57)$ & $12 / 51(23.53)$ \\
\hline -Number transferring $>0$ (\%) & “ & “ & $35 / 49(71.43)$ & $39 / 51(76.47)$ \\
\hline -Number transferring all (\%) & “ & “ & $24 / 49(48.98)$ & $18 / 51(35.29)$ \\
\hline Mean percent. embezzled & “ & “ & 39.79 & 44.78 \\
\hline Mean final earnings in TS & 6833.33 & 6950 & 6083.33 & 6000 \\
\hline \multicolumn{5}{|l|}{ Intermediary 2} \\
\hline Number receiving $>0 /$ total $(\%)$ & - & - & $35 / 60(58.33)$ & $39 / 60(65)$ \\
\hline -Number transferring $0(\%)$ & - & - & $14 / 35(40)$ & $16 / 39(41.03)$ \\
\hline -Number transferring $>0$ (\%) & - & - & $21 / 35(60)$ & $23 / 39(58.97)$ \\
\hline -Number transferring all (\%) & - & - & $10 / 35(28.57)$ & $15 / 39(38.46)$ \\
\hline Mean percent. embezzled & - & - & 60.69 & 52.14 \\
\hline Mean final earnings in TS & - & - & 6350 & 5583.33 \\
\hline
\end{tabular}

Notes: The percentages embezzled are conditional on receiving a positive amount from the previous player. "Mean total percent. embezzled" corresponds to the amount not transferred*100/amount sent by the sender. "Mean percent. embezzled" corresponds to the amount not transferred*100/amount received from the previous player.

Consistent with Conjecture 1 for intermediaries, Table 4 indicates that in all treatments, conditional on receiving a positive amount, a majority of intermediaries transfer some money to the next player. This is the case for $56 \%$ of the intermediaries in 1 -Int-NI, $77.5 \%$ in 1 -Int-I, $66.67 \%$ in 2-Int-NI, and $68.89 \%$ in 2-Int-I. The share of players who embezzle fully is $44 \%$ in 1 - 
Int-NI and $33.33 \%$ in 2-Int-NI, but the difference is not significant (proportion test: $p=0.277$ ). On the opposite side, the share of intermediaries who transfer the whole amount received is higher in 2-Int-NI $(40.48 \%)$ than in 1-Int-NI $(24 \%)$ (proportion test: $p=0.052)$. The mean percentage of the amount received from the previous player that is embezzled by an intermediary is marginally lower in 2-Int-NI (48.49\%) than in 1-Int-NI (62.04\%; M-W test: $p=0.085) .^{22}$ This is driven by the behavior of the first intermediaries. Indeed, our data indicate that when there is no transparency first intermediaries embezzle significantly less than intermediaries in short chains $(39.79 \%$ vs. $62.04 \%$; $p=0.014)$, while the second intermediaries embezzle more than the first ones $(60.69 \% ; p=0.053)$ and as much as single intermediaries in 1-Int-NI $(p=0.818)$. This finding holds for different levels of donations, as shown in Figure A1 in Appendix 4.

However, the previous analysis does not control for the amount received and thus, for differences in senders' behavior across treatments. This is why we turn to a regression analysis. Table 5 reports the marginal effects from five Tobit models in which the dependent variable is the share of the amount received that is embezzled by a subject, from 0 to 1 . We use Tobit models since observations are censored both on the left and on the right. Model (1) pools the data of all treatments with intermediaries, with the short transfer chain taken as the reference category. Models (2) and (3) are variants of model (1) that exclude either the first intermediary or the second intermediary in the long chains. The aim is to test whether the position in long chains matters compared to short chains. Models (4) and (5) consider 2-Int-I and 2-Int-NI, respectively, to identify possible differences in the behavior of first and second intermediaries in long chains. Standard errors are clustered at the matched group level when both intermediaries in long chains are included. ${ }^{23}$ The independent variables include a dummy for the long chain treatment and a dummy for transparency in the first three models. In models (4) and (5), they include a dummy

\footnotetext{
22 These percentages indicate that intermediaries transfer a much higher share of the amount received than senders. This confirms that intermediaries did not play as in a dictator game and that they understood that their role is to transfer money to the recipients.

${ }^{23}$ Clustering at the group level is useful since the two intermediaries are not independent.
} 
variable indicating whether the subject is the first intermediary. All the regressions control for the amount received from the previous player, the experimental location and the same sociodemographic controls as in Table 3. Similar models without socio-demographic variables are reported in Appendix Table A2; they deliver qualitatively similar results.

Table 5. Determinants of the share of the amount received that is embezzled by an intermediary

\begin{tabular}{|c|c|c|c|c|c|}
\hline $\begin{array}{l}\text { Dep. variable } \\
\text { Share embezzled }\end{array}$ & $\begin{array}{l}\text { All } \\
(1)\end{array}$ & $\begin{array}{l}\text { Excluding } 1^{\text {st }} \\
\text { intermediary } \\
\text { (2) }\end{array}$ & $\begin{array}{l}\text { Excluding } 2^{\text {nd }} \\
\text { intermediary } \\
\text { (3) }\end{array}$ & $\begin{array}{l}\text { Long chain } \\
\text { Transparency } \\
\text { (4) }\end{array}$ & $\begin{array}{l}\text { Long chain No } \\
\text { Transparency } \\
\text { (5) }\end{array}$ \\
\hline Short chain & Ref. & Ref. & Ref. & - & - \\
\hline Long chain & $\begin{array}{c}-0.025 * * \\
(0.011)\end{array}$ & $\begin{array}{l}-0.007 \\
(0.016)\end{array}$ & $\begin{array}{c}-0.039 * * \\
(0.015)\end{array}$ & - & - \\
\hline Transparency & $\begin{array}{l}-0.014 \\
(0.010)\end{array}$ & $\begin{array}{l}-0.027^{*} \\
(0.015)\end{array}$ & $\begin{array}{l}-0.011 \\
(0.014)\end{array}$ & - & - \\
\hline $1^{\text {st }}$ intermediary & - & - & - & $\begin{array}{l}-0.009 \\
(0.019)\end{array}$ & $\begin{array}{c}-0.046^{* *} \\
(0.023)\end{array}$ \\
\hline $\begin{array}{l}\text { Amount received } \\
\text { (rescaled) }\end{array}$ & $\begin{array}{c}-0.004 * * \\
(0.002)\end{array}$ & $\begin{array}{l}-0.003 \\
(0.002)\end{array}$ & $\begin{array}{c}-0.005^{* *} \\
(0.002)\end{array}$ & $\begin{array}{l}-0.005 \\
(0.004)\end{array}$ & $\begin{array}{c}-0.006^{* *} \\
(0.003)\end{array}$ \\
\hline Dar-es-Salaam & $\begin{array}{c}0.049 * * * \\
(0.012)\end{array}$ & $\begin{array}{c}0.075 * * * \\
(0.018)\end{array}$ & $\begin{array}{c}0.051 * * * \\
(0.016)\end{array}$ & $\begin{array}{c}0.010 \\
(0.020)\end{array}$ & $\begin{array}{c}0.085^{* * * *} \\
(0.028)\end{array}$ \\
\hline Male & $\begin{array}{c}0.036^{* * * *} \\
(0.013)\end{array}$ & $\begin{array}{c}0.050 * * * \\
(0.018)\end{array}$ & $\begin{array}{c}0.024 \\
(0.016)\end{array}$ & $\begin{array}{c}0.023 \\
(0.021)\end{array}$ & $\begin{array}{l}0.071 * * \\
(0.029)\end{array}$ \\
\hline Age & $\begin{array}{l}-0.003^{*} \\
(0.002)\end{array}$ & $\begin{array}{l}-0.001 \\
(0.003)\end{array}$ & $\begin{array}{l}-0.006 * * \\
(0.003)\end{array}$ & $\begin{array}{l}-0.005 \\
(0.007)\end{array}$ & $\begin{array}{l}-0.007 * \\
(0.004)\end{array}$ \\
\hline Married & $\begin{array}{c}0.022 \\
(0.025)\end{array}$ & $\begin{array}{c}0.019 \\
(0.031)\end{array}$ & $\begin{array}{r}0.079 * * \\
(0.039)\end{array}$ & $\begin{array}{l}0.013 \\
(0.073)\end{array}$ & $\begin{array}{l}-0.065 \\
(0.050)\end{array}$ \\
\hline Christian & $\begin{array}{l}-0.022 \\
(0.014)\end{array}$ & $\begin{array}{l}-0.011 \\
(0.019)\end{array}$ & $\begin{array}{c}-0.046^{* *} \\
(0.021)\end{array}$ & $\begin{array}{l}-0.002 \\
(0.019)\end{array}$ & $\begin{array}{l}-0.041 \\
(0.029)\end{array}$ \\
\hline Religious practice & $\begin{array}{l}-0.008 * \\
(0.005)\end{array}$ & $\begin{array}{l}-0.013^{*} \\
(0.007)\end{array}$ & $\begin{array}{c}-0.015^{* *} \\
(0.007) \\
\end{array}$ & $\begin{array}{c}0.002 \\
(0.010) \\
\end{array}$ & $\begin{array}{l}-0.003 \\
(0.008)\end{array}$ \\
\hline Number of obs. & 261 & 161 & 190 & 88 & 83 \\
\hline Left/right cens. obs. & $90 / 87$ & $48 / 61$ & $66 / 57$ & $32 / 28$ & $34 / 28$ \\
\hline Log pseudo-likelih. & -264.228 & -155.631 & -187.958 & -94.281 & -71.865 \\
\hline Prob $>$ Chi 2 & $<0.001$ & 0.001 & $<0.001$ & 0.704 & 0.005 \\
\hline Pseudo $\mathrm{R}^{2}$ & 0.074 & 0.110 & 0.093 & 0.019 & 0.197 \\
\hline
\end{tabular}

Notes: Table 5 reports marginal effects from Tobit models. Robust standard errors clustered at the group level (since the two intermediaries are not independent) are in parentheses. The dependent variable takes values between 0 and 1. To facilitate the reading of the Table, the amount received from the previous player (either the donor or the first intermediary) has been rescaled (real amount divided by 1000), such that it can be read as the mean number of bills of TS 1000 received. Left censored observations correspond to no embezzlement and right-censored observations to full embezzlement. 2 observations on religious practice are missing (one in 2-Int-I and one in 2-Int-NI) and one observation on gender is missing in 2 -Int-I. ***, $* *$, and $*$ indicate significance at the $0.01,0.05$, and 0.10 level, respectively.

Model (1) in Table 5 indicates that the percentage of the amount received that is embezzled is 2.5 percentage points lower in long chains than in short chains, and this is significant at the $5 \%$ level. This is in contrast to Conjecture 3. Models (2) and (3) excluding either the first or the second intermediary in long chains reveal that first intermediaries in long chains embezzle 3.9 
percentage points less than single intermediaries in short chains while second intermediaries do not differ from single intermediaries. Models (4) and (5) confirm that first intermediaries differ significantly from second ones, but only in the absence of transparency where they embezzle 4.6 points less than the following intermediary. A possible interpretation of this finding is that if the first intermediary anticipates embezzlement after him and if he cares about the receiver's welfare to some extent, he may be more willing to resist the temptation to embezzle. Another interpretation is in terms of kindness toward the next intermediary. This would suggest to model inequality aversion and guilt aversion with role-dependent preferences. Thus, the higher total percentage embezzled that was observed at the aggregate level in long chains in Figure 1 results from a mechanical effect due to the presence of more intermediaries, and not from a higher individual rate of embezzlement driven by a dilution of responsibility among more intermediaries.

Table 5 also reveals that when the amount received is larger, a lower percentage of the donation is embezzled. This seems to be driven mainly by first intermediaries in long chains. Possible explanations may be that when observing a more generous donation, intermediaries with an income target can take a lower share of it. ${ }^{24}$ Interestingly, embezzlement is decreased by a more intense religious practice, suggesting that moral concerns and self-image were activated during the game. Lastly, while donation behavior was similar in the two campuses, embezzlement is larger in Dar-es-Salaam. We have no direct explanation for this finding and we can only speculate that living in big cities exposes individuals to others' dishonesty more frequently, which may contribute to weaken their moral values of honesty.

We summarize our findings on intermediaries' individual behavior in the absence of transparency as follows:

\footnotetext{
24 This result is unlikely driven by the intermediaries' willingness to equalize their payoff with that of the recipients. Indeed, conditional on receiving at last TS3000, only $11.76 \%$ of the intermediaries transfer 3000 (which would equalize the recipient's payoff and the initial endowment of the intermediary). More generally, the final payoff of the recipient is equal to that of the intermediary in only 13 observations out of 360 .
} 
Result 3 (Embezzlement, individual level): Controlling for the amount received, intermediaries embezzle less, the longer the transfer chain; this is due to less embezzlement at the beginning of the chain.

\subsection{Embezzlement and Transparency}

In this sub-section, we examine the impact of introducing transparency on the intermediaries' behavior. Table 4 indicates that transparency reduces the total percentage of the donation that is embezzled. However, the decrease is significant neither in short chains $(50.55 \%$ in 1 -Int-I compared to $62.04 \%$ in 1 -Int-NI; $p=0.121)$ nor in long chains $(71.76 \%$ in 2 -Int-I compared to $74.88 \%$ in 2-Int-NI; $p=0.701) .{ }^{25}$ Table 4 also shows that transparency decreases the percentage of intermediaries who embezzle fully. However, this is significant only in short chains. Indeed, this percentage is $22.5 \%$ in 1 -Int-I, while it was $44 \%$ in 1 -Int-NI $(p=0.033)$; it is $31.11 \%$ in 2 -IntI and $33.33 \%$ in 2 -Int-NI $(p=0.754)$. This could be explained by guilt from blame when the donor can identify the responsibility of the person.

In long chains with transparency, second intermediaries embezzle a lower percentage of the donation than without transparency $(52.14 \%$ in 2-Int-I instead of $60.69 \%$ in 2-Int-NI), whereas first intermediaries embezzle more (44.78\% instead of 39.79\%). This echoes models (4) and (5) in Table 5 showing that first and second intermediaries behave similarly once transparency is introduced. However, none of these effects is significant ( $p=0.575$ and $p=0.485$, respectively).

At the individual level, controlling for the amount received, models (1) and (2) in Table A3 in Appendix indicate that in short chains the percentage embezzled is five points lower in 1-IntI compared to 1-Int-NI but this effect is only marginally significant and conditional on controlling for individual characteristics ( $p=0.069)$. For long chains, models (3) and (4) find no effect of transparency. Overall, our experiment fails finding a positive effect of transparency on honesty, regardless of the length of the transfer chain.

\footnotetext{
${ }^{25}$ Considering the mean percentage embezzled (47.97\% in 2-Int-I) instead of the total percentage does not change the conclusion ( $p=0.995$ when compared to 2 -Int-NI and $p=0.876$ when compared to 1-Int-I).
} 
We summarize our findings relative to the impact of introducing transparency as follows:

Result 4 (Embezzlement, transparency): There is no significant positive effect of transparency on the honesty of transfers.

Result 4 does not support Conjecture 4 stating that transparency should decrease embezzlement in short chains if intermediaries are sensitive to guilt from blame. Either our intermediaries are not sensitive to guilt from blame or their sensitivity is too low to be effective.

\subsection{Recipients' Earnings}

We finally examine the recipients' earnings. Figure 2 displays the mean amount received by recipients, by treatment, and Table 6 reports summary statistics about these earnings.

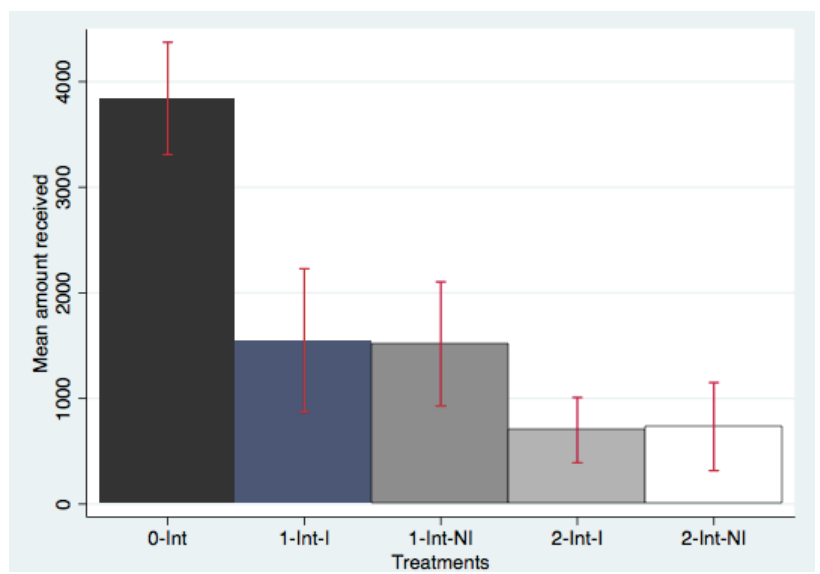

Figure 2. Mean amount actually received by the recipients, by treatment

Table 6. Summary statistics - Recipients' earnings

\begin{tabular}{|c|c|c|c|c|c|}
\hline Treatments & 0 -Int & 1-Int-I & 1-Int-NI & 2-Int-I & 2-Int-NI \\
\hline $\begin{array}{l}\mathrm{Nb} \text { receiving amount }>0 / \text { total } \\
(\%)\end{array}$ & $\begin{array}{l}110 / 120 \\
(91.67)\end{array}$ & $\begin{array}{l}31 / 60 \\
(51.67)\end{array}$ & $\begin{array}{c}28 / 60 \\
(46.67)\end{array}$ & $\begin{array}{l}23 / 60 \\
(38.33)\end{array}$ & $\begin{array}{c}21 / 60 \\
(35.00)\end{array}$ \\
\hline Mean amount received in TS & 3841.67 & 1550 & 1516.67 & 700 & 733.33 \\
\hline $\begin{array}{l}\text { Mean \% received from the } \\
\text { sender's endowment }\end{array}$ & 25.61 & 10.33 & 10.11 & 4.67 & 4.89 \\
\hline $\begin{array}{l}\text { Mean \% received from the } \\
\text { donation }\end{array}$ & 100 & 49.45 & 37.96 & 28.23 & 25.12 \\
\hline Mean final earnings in TS & 5841.67 & 3550 & 3516.67 & 2700 & 2733.33 \\
\hline
\end{tabular}

Notes: The mean amounts received (in TS) include amounts equal to 0. "Mean percent. received from the sender's endowment" corresponds to the amount received*100/15000. "Mean percent. received from the donation" corresponds to the amount received*100/amount donated by the sender. 
Figure 2 and Table 6 show that, compared to the simple dictator game ( 0 -Int treatment), the presence of a single intermediary lowers by $60.09 \%$ the mean amount actually received by the recipient. Introducing a second intermediary leads to a total decrease by $81.34 \%$ compared to the 0-Int treatment. The amount actually received is lower in each treatment with intermediaries compared to 0 -Int $(p<0.001$ in each pairwise comparison). The amount received decreases significantly in the number of intermediaries ( $p=0.069$ for 2-Int-NI $v s$. 1-Int-NI; $p=0.049$ for 2Int-I vs. 1-Int-I). In contrast, transparency does not affect significantly the amount received ( $p=0.817$ with one intermediary and $p=0.762$ with two).

To control for the amount donated initially, Table 7 reports the marginal effects from three Tobit regressions in which the dependent variable is the amount received by the recipient. In model (1), the independent variables include three dummy variables for transparency, short and long transfer chains with 0 -Int as the reference category, the initial donation, and a control for the experimental location. Model (2) is similar to (1), except that it includes only the observations from the treatments with transparency (0-Int, 1-Int-I and 2-Int-I). Model (3) includes only the observations from the treatments without transparency (1-Int-NI and 2-Int-NI). Here, we do not control for individual characteristics since receivers do not make any decision.

Table 7. Determinants of the amount received by the Recipient

\begin{tabular}{lccc}
\hline Dep. variable & All & Transparency & No Transparency \\
Amount received & $(1)$ & $(2)$ & - \\
\hline No intermediary & Ref. & Ref. & \\
& & & Ref. \\
Short chain & $-1242.891^{* * *}$ & $-1579.976^{* * *}$ & $(144.25)$ \\
& $(137.43)$ & $-1596.632^{* * *}$ & $-400.481^{* *}$ \\
Long chain & $-1514.715^{* * *}$ & $(147.14)$ & $(184.78)$ \\
& $(137.43)$ & - & - \\
Transparency & 206.894 & & \\
& $(154.24)$ & $-515.374 * * *$ & $-1057.702 * * *$ \\
Dar-es-Salaam & $-715.589 * * *$ & $(163.21)$ & $(202.20)$ \\
& $(124.86)$ & $0.521 * * *$ & $0.217 * * *$ \\
Amount initially & $0.370 * * *$ & $(0.03)$ & $(0.031)$ \\
sent by the sender & $(0.022)$ & 240 & 120 \\
\hline Number of obs. & 360 & $76 / 3$ & $71 / 0$ \\
Left/right cens. obs. & $147 / 3$ & -1475.236 & -485.884 \\
Log pseudo-likelih. & -1980.221 & $<0.001$ & $<0.001$ \\
Prob $>$ Chi2 & $<0.001$ & 0.096 & 0.061 \\
Pseudo R ${ }^{2}$ & 0.085 & & \\
\hline
\end{tabular}


Notes: Table 7 reports marginal effects from Tobit estimates. Standard errors are in parentheses. Left censored observations correspond to receiving $0 \mathrm{TS}$ and right-censored observations to receiving $15000 \mathrm{TS}$. ${ }^{* * *}$ and $* *$ indicate significance at the 0.01 and 0.05 level, respectively.

The estimates confirm the descriptive statistics. Model (1) shows that introducing intermediaries decreases the amount received, especially when the transfer chain is long (the marginal effects of the short vs. long chains differ significantly: $p=0.035)$. By contrast, transparency does not impact this amount. Increasing the length of the transfer chain has a significant negative effect on the recipients' earnings when donations are not transparent (see model (3)). This is not the case when they are transparent (see model (2); $p=0.922$ ).

We now state our last result, which derives naturally from the previous findings.

Result 5 (Receivers' earnings): Controlling for initial donations, the recipients' mean earnings decrease in the number of intermediaries overall and in the absence of transparency. Transparency itself has no direct effect on recipients' earnings.

\section{Discussion and Conclusion}

We have studied experimentally how the extent of embezzlement is affected by the length of the transfer chain between a donor and a recipient and by the disclosure of information about donations. We have shown that while some intermediaries resist the temptation of embezzling donations and others appropriate everything, embezzlement is most of the time incomplete even in the absence of sanctions. This is consistent with previous literature showing that most people do not exploit their cheating opportunities in full in order to keep a good image of themselves (e.g., Mazar et al., 2008; Fischbacher and Föllmi-Heusi, 2013) or because of perceived cheating aversion (e.g., Dufwenberg and Dufwenberg, 2018; Gneezy et al. 2019; Abeler et al. 2019). We extend the literature on the heterogeneity of attitudes towards dishonesty (Gibson et al., 2013) by showing that the latter may also depend on the position in the decision chain.

We have shown that controlling for the amount donated, the recipients' earnings from donations decrease in the number of intermediaries when recipients are not informed about the amount donated initially. The higher total percentage of the donations embezzled in long transfer 
chains observed at the aggregate level results from the larger number of intermediaries in a position to take money. This is not driven by a weaker moral firmness of each intermediary, although they can hide behind each other in longer chains. On the opposite, the first intermediary in long chains embezzles a lower percentage of the donation than the second intermediary or than the single intermediary in short chains when there is no transparency. This contradicts the replacement logic according to which an individual becomes more likely to take a dishonest action if he expects that if he does not do it himself, somebody else will do it after him. This finding is consistent with those of Bartling and Özdemir (2017) who show that the replacement excuse is not used when the social norm is clear. The interpretation could be in terms of social preferences: either the first intermediaries try to compensate for the anticipated dishonesty of others because they care more about the receiver's payoff, or they embezzle less for letting second intermediaries take their share. Our design does not allow us to disentangle between these interpretations but our results suggest to adjust models of inequality aversion and guilt aversion by varying the weight put on each other player.

Our results suggest that shortening the transfer chain would improve the welfare of recipients because of the mechanical effect of the chain size. The policy message regarding transparency is not as straightforward. Indeed, our analysis shows that at the individual level, the mean percentage embezzled is lower when receivers know the amount initially donated, i.e., when social judgment by other players is made possible and individual responsibility is clearly identified. But the effect does not reach standard levels of significance. At the aggregate level, transparency has no significant impact either on the proportion embezzled. At this stage, it is interesting to recall that Salmon and Serra (2017) found that social judgment can reduce corruption but only for those subjects who identify with a culture of low corruption. Our experiment has been conducted in a country where corruption is widespread, which may limit the effects of transparency on unethical behavior. 
Of course, we acknowledge some limitations of our study. Although it tries to capture major aspects of embezzlement in real settings, our design represents a stylized environment: we use a one-shot, zero-sum game, with a minimal notion of transparency without any risk of sanctions and with passive receivers. In real settings the effectiveness of transparency may depend on more dimensions, including the simplicity of administrative rules, the standards in accounting, critical media, strong civil norms and values (e.g., de Vries and Sobis, 2016). The way we implemented transparency (by simply informing the receiver about the original donation) may have provided too subtle incentives for intermediaries to behave more honestly. Moreover, anonymity of subjects was guaranteed by the experimenter and subjects were only identifiable through an anonymous identifier; also, participants did not have to report anything to the experimenter to get paid since they received directly their earnings in the bag. However, participants could anticipate that the experimenter knew the amount that was donated by the sender and thus, he was able to measure the amount embezzled. This may have activated image concerns even in the absence of transparency.

Several extensions can be thought of. It would be interesting to study how repeated interactions affect embezzlement and to explore other means of implementing transparency. For example, senders could be informed ex post about the final amount actually transferred to the receiver and intermediaries would be made aware of this. This form of transparency could be more effective in the case of a single intermediary who might feel more guilty, both with respect to the sender and to the receiver. Eliciting beliefs of the sender and the intermediaries as well as of the recipient could be useful to understand the decisions of each party. Allowing intermediaries to observe the (dis)honesty of the previous individuals in the chain would enable us to measure peer effects. It is indeed possible that the share embezzled by the first intermediary in long chains would increase or decrease the share embezzled by the second intermediary. 
Other manipulations could include the introduction of negative externalities of embezzlement, variations in the organization of the transfer chain (e.g., introducing elected intermediaries) or in the intermediaries' relative income. We have found that embezzlement was more likely in the campus located in the bigger city than in the rural area, and we could only speculate that it was perhaps driven by a more frequent exposure of individuals to crime in large cities. Replications in other countries and in various locations within each country (e.g., rural vs. urban areas) would help appreciate the role of social and civic norms and study whether transparency would have a stronger effect when norms are stronger. This is left for further investigation. 


\section{Reference list}

Abbink, K., Irlenbusch, B., Renner, E. (2002). An Experimental Bribery Game. Journal of Law, Economics, and Organization 18(2), 428-454.

Abbink, K., Ellmann, M. (2010). The donor problem: an experimental analysis of beneficiary empowerment. Journal of Development Studies 46(8), 1327-1344.

Abbink, K., Herrmann, B. (2011). The moral cost of nastiness. Economic Inquiry 49(2), 631633.

Abbink, K., Serra, D. (2012). Anti-corruption policies: Lessons from the lab. In D. Serra \& L. Wantchekon (Eds.), New advances in experimental research on corruption (Vol. 15). Bingley: Emerald Group Publishing

Abeler, J., Becker, A., Falk, A. (2014). Representative evidence on lying costs. Journal of Public Economics 113, 96-104.

Abeler, J., Nosenzo, D., Raymond, C. (2019). Preferences for truth-telling. Econometrica, 87(4), $1115-1153$.

Armantier, O. and A. Boly (2011). A controlled field experiment on corruption. European Economic Review 55, 1072-1082.

Armantier, O. and A. Boly (2012). On the External Validity of Corruption Experiments. In D. Serra and L. Wantchekon (Eds.) New Advances in Experimental Research on Corruption, Research in Experimental Economics, Volume 15. Emerald Group Publishing.

Attanasi, G., Rimbaud, C., Villeval, M.C. (2019). Embezzlement and guilt aversion. Journal of Economic Behavior \& Organization 167, 409-429.

Azfar, O., Nelson, W.R. (2007). Transparency, Wages, and the Separation of Powers: An Experimental Analysis of Corruption. Public Choice 130(3-4), 471-493.

Bahr, G., Requate, T. Reciprocity and Giving in a Consecutive Three-Person Dictator Game with Social Interaction. German Economic Review 15(3), 374-392.

Banerjee, A., Hanna, R., Mullainathan, S. (2012). Corruption. In R. Gibbons and J. Roberts (Eds.), Handbook of organizational economics, Princeton: Princeton University Press.

Banerjee, R., Baul, T., Rosenblat, T. (2015). On self-selection of the corrupt into the public sector. Economics Letters 127, 43-46.

Banerjee, A., Hanna, R., Kyle, J., Olken, B.A., Sumarto, S. (2018). Tangible information and citizen empowerment: Identification cards and food subsidy programs in Indonesia. Journal of Political Economy 126(2), 451-491.

Banerjee, A., Duflo, E., Imbert, C., Mathew, S., Pande, R. (2019). Egovernance, Accountability, and Leakage in Public Programs: Experimental Evidence from a Financial Management Reform in India. American Economic Journal: Applied Economics. Forthcoming.

Banuri, S., Eckel, C. (2015). Cracking down on bribery. Social Choice and Welfare 45, 579-600.

Bardhan, P. (1997). Corruption and development: A review of issues. Journal of Economic Literature 35, 1320-1346.

Barr, A., Lindelöw, M., Serneels, P. (2009). Corruption in public service delivery: An experimental analysis. Journal of Economic Behavior \& Organization 72, 225-239.

Barr, A., Serra, D. (2010). Corruption and culture: An experimental analysis. Journal of Public 
Economics 194, 862-869.

Bartling, B., Fischbacher, U. (2012). Shifting the Blame: On Delegation and Responsibility. Review of Economic Studies 79 (1), 67-87.

Bartling, B., Özdemir, Y. (2017). The limits to moral erosion in markets: Social norms and the replacement excuse. Working Paper, University of Zurich.

Battigalli, P., Dufwenberg, M. (2007). Guilt in Games. American Economic Review 97 (2), 170176.

Beekman, G., Bulte, E., Nillesen, E. (2014). Corruption, investments and contributions to public goods: Experimental evidence from rural Liberia. Journal of Public Economics 115, 34-47.

Bertrand, M., Djankov, S., Hanna, R., Mullainthan, S. (2007). Obtaining a Driving License in India: An Experimental Approach to Studying Corruption. The Quarterly Journal of Economics, November 122(4), 1639-1676

Bucciol, A., Piovesan, M. (2011). Luck or cheating? A field experiment on honesty with children. Journal of Economic Psychology 32 (1), 73-78.

Cameron, L., Chaudhuri, A., Erkal, N., Gangadharan, L. (2009). Propensities to engage in and punish corrupt behavior: Experimental evidence from Australia, India, Indonesia and Singapore. Journal of Public Economics 93(7-8), 843-851.

Chlaß, N., Gangadharan, L., Jones, K. (2015). Charitable Giving and Intermediation. Discussion Paper 18/15. Monash Business School.

Coffman, L.C. (2011). Intermediation reduces punishment (and reward). American Economic Journal: Microeconomics 3, 77-106.

Cohn, A., Maréchal, M.A., Noll, T. (2015). Bad Boys: How Criminal Identity Salience Affects Rule Violation. Review of Economic Studies 82 (4), 1289-1308.

Dai, Z., Galeotti, F., Villeval, M.C. (2018). Cheating in the lab predicts fraud in the field. An experiment in public transportations. Management Science 64 (3), 1081-1100.

Dana, J., Weber, R., Kuang J.X. (2007). Exploiting Moral Wriggle Room: Experiments demonstrating an illusory preference for fairness. Economic Theory 33, 67-80.

de Vries, M., Sobis, I. (2016). Increasing transparency is not always the panacea. International Journal of Public Sector Management 29(3), 255-270.

Dimant, E., Tosato, G. (2018). Causes and effects of corruption: What has past decade's empirical research taught us? A survey. Journal of Economic Surveys. 32(2), 335-356.

Drèze, J., Khera, R. (2015). Understanding leakages in the public distribution system. Economic and Political Weekly 50(7), 39-42.

Drugov, M., Hamman, J., Serra, D. (2014). Intermediaries in Corruption: An Experiment. Experimental Economics 17(1), 78-99.

Dufwenberg M., Dufwenberg M.A. (2018). Lies in Disguise-A Theoretical Analysis of Cheating. Journal of Economic Theory 175, 248-264.

Fan, C.S., Lin, C. Treisman, D. (2010). Embezzlement Versus Bribery, National Bureau of Economic Research Working Paper 16542, http://www.nber.org/papers/w16542.

Fantaye, D.K. (2004). Fighting Corruption and Embezzlement in Third World Countries. Journal of Criminal Law 68(2), 170-176. 
Fershtman, C., Gneezy, U. (2001). Strategic Delegation: An Experiment. RAND Journal of Economics 32(2), 352-368.

Fischbacher, U., Föllmi-Heusi, F. (2013). Lies in disguise: An experimental study on cheating. Journal of the European Economic Association 11, 525-547.

Forsythe, R., Horowitz, J., Savin, N. E., Sefton, M. (1994). Fairness in simple bargaining experiments. Games and Economic Behavior 6, 347-369.Gächter, S., Schultz, J.F. (2016). Intrinsic honesty and the prevalence of rule violations across societies. Nature 531, 24 March, 496-499.

Gibson, R., Tanner, C., Wagner, A. F. (2013). Preferences for truthfulness: Heterogeneity among and within individuals. American Economic Review 103, 532-548.

Gneezy, U., Saccardo, S., van Veldhuizen (2015). Bribery: Greed versus Reciprocity. Mimeo.

Gneezy, U., Kajackaite, A., Sobel, J. (2018). Lying Aversion and the Size of the Lie . American Economic Review 108 (2), 419-453.

Gray, H.S. (2015). The political economy of grand corruption in Tanzania. African Affairs 114/456, 382-403.

Green, G. (1993). White-collar crime and the study of embezzlement. Annals of the American Academy of Political and Social Science 525, 95-106.

Güth, W., Huck, S., Ockenfels, P. (1996). Two-level ultimatum bargaining with incomplete information. The Economic Journal 106(436), 593-604.

Hamman, J.R., Loewenstein, G., Weber, R.A. (2010). Self-Interest through Delegation: An Additional Rationale for the Principal-Agent Relationship. American Economic Review 100 (4), 1826-1846.

Hanna, R., Wang, S.Y. (2015). Dishonesty and Selection into Public Service. Working paper, Harvard University.

Hasker, K., Okten, C. (2008). Intermediaries and Corruption. Journal of Economic Behavior \& Organization 67, 103-115.

Hoffman, E., McCabe, K., Shachat, K. and Smith, V. (1994). Preferences, property rights and anonymity in bargaining games. Games and Economic Behavior 7, 346-380.

Houser, D., Vetter, S., Winter, J. (2012). Fairness and cheating. European Economic Review 56, 1645-1655.

Huck, S. (1999). Responder behavior in ultimatum offer games with incomplete information. Journal of Economic Psychology 20, 183-206.

Imbert, C., Papp, J. (2011). Estimating leakages in India's employment guarantee. In Khera, R., (ed.). The Battle for Employment Guarantee, Oxford University Press.

Kajackaite, A., Gneezy, U. (2017). Lying costs and incentives. Games and Economic Behavior $102,433-444$

Kolstad, I., Wiig, A. (2009). Is Transparency the Key to Reducing Corruption in Resource-Rich Countries? World Development 37(3), 521-532.

Lindstedt, C., Naurin, D. (2010). Transparency is not Enough: Making Transparency Effective in Reducing Corruption. International Political Science Review 31 (3), 301-322.

List, J.A. (2009). The economics of open air markets. NBER Working Paper 15420. 
Makowsky, M. D., and Wang, S. (2015). Embezzlement, Whistleblowing, and Organizational Structure. Mimeo.

Mazar, N., Amir, O., Ariely, D. (2008). The dishonesty of honest people: A theory of self-concept maintenance. Journal of Marketing Research 45, 633-644.

Muralidharan, K., Niehaus, P., Sukhtankar, S. (2016). Building state capacity: Evidence from biometric smartcards in India. American Economic Review 106(10), 28952929.

Niehaus, P., Sukhtankar, S. (2013). Corruption dynamics: The golden goose effect. American Economic Journal: Economic Policy 5(4), 230-269.

Olken, B.A. (2006). Corruption and the costs of redistribution: Micro evidence from Indonesia. Journal of Public Economics 90, 853-870.

Olken, B.A. (2007). Monitoring Corruption: Evidence from a Field Experiment in Indonesia. Journal of Political Economy 115(2), 200-249.

Olken, B.A., Pande, R. (2011). Corruption in developing countries. NBER Working Paper 17398. http://www.nber.org/papers/w17398

Platteau, J.-P. (2004). Monitoring elite capture in community-driven development. Development and Change 35(2), 225-248.

Rapoport, A., Sundali, J.A. (1996). Ultimatums in two-person bargaining with one-sided uncertainty: Offer games. International Journal of Game Theory 25(4), 475-494.

Reinikka, R., Svensson, J. (2004). Local capture: evidence from a central government transfer program in Uganda. The Quarterly Journal of Economics 119, 679-705.

Reinikka, R., Svensson, J. (2011). The power of information in public services: Evidence from education in Uganda. Journal of Public Economics 95, 956-966.

Rietz, T.A., Sheremata, R., Shields, T.W., Smith, V.L. (2013). Transparency, efficiency and the distribution of economic welfare in pass-through investment trust games. Journal of Economic Behavior \& Organization 94, 257-267.

Rose-Ackerman, S. (1975). The Economics of Corruption. Journal of Public Economics 4, 1-17.

Salmon, T., Serra, D. (2017). Corruption, Social Judgment and Culture: An Experiment. Working Paper Southern Methodist University. http://dx.doi.org/10.2139/ssrn.2383903

Sequeira, S. (2016). Corruption, Trade Costs and Gains from Tariff Liberalization: Evidence from Southern Africa. Mimeo.

Serra, D., Wantchekon, L. (Eds.) (2012). New Advances in Experimental Research on Corruption, Research in Experimental Economics, Volume 15. Emerald Group Publishing.

Shalvi, S., Dana, J., Handgraaf, M.J.J., De Dreu, C.K.W. (2011). Justified ethicality: observing desired counterfactuals modifies ethical perceptions and behavior. Organizational Behavior and Human Decision Processes 115, 181-190.

Shleifer, R., Vishny R.W. (1993). Corruption. The Quarterly Journal of Economics 108(3), 599617.

Transparency International (2014). Corruption perceptions index 2014. www.transparency.org.

Vicente, P. (2010). Does Oil Corrupt? Evidence from a Natural Experiment in West Africa, Journal of Development Economics 92(1), 28-38. 
Winschel, E., Zahn, P. (2014). When Ignorance is Bliss. Information Asymmetries Enhance Prosocial Behavior in Dictator Games. University of Mannheim, Working Paper 13-07. 


\section{Appendix 1. Instructions \\ Instructions for the 1-Int-NI treatment \\ (The differences with the 1-Int-I treatment are indicated in italics)}

We thank you for your participation in this experiment on decision-making. During this experiment, you will be able to earn Tanzanian Shillings (TS) in cash. Your decisions or responses to questions will be strictly anonymous and confidential. You will be identified only by an id code throughout the experiment.

In this experiment, we randomly form groups of three people. Each group consists of one person A, one person B and one person $\mathrm{C}$. The identity of the other group members will remain anonymous throughout the experiment.

After reading the instructions, each of you will be randomly assigned to one of three different rooms that correspond to the three different roles. Once in the room, all the participants in this room will be assigned the same role. This means that all the participants A will be in the same room; all the participants B will be in another room and all the participants $\mathrm{C}$ will be in a third room. Once in your room, you will learn your role and you will never meet again the participants in the other roles.

\section{The task}

At the beginning of the experiment in each group, person A receives 15000 TS. Person B receives 5000 TS. Person $\mathrm{C}$ receives $2000 \mathrm{TS}$.

Person A has to decide how many TS to transfer to person C. Person A can choose any amount between 0 and 15 $000 \mathrm{TS}$, as multiples of $1000 \mathrm{TS}$ (either $0,1000,2000, \ldots ., 15000$ ).

If person A sends money to person $\mathrm{C}$, the transfer has to be done through an intermediary, person $\mathrm{B}$. The role of person $\mathrm{B}$ is to transfer the money to person C. Person B is not allowed to transfer his own TS to person C.

Person $\mathrm{C}$ has no decision to make.

\section{If you are a person $A$}

You will receive a bag marked with the id number of your group of three. This bag contains two envelopes, white and brown.

- The white envelope contains 15000 TS.

- $\quad$ The brown envelope is empty and you can use it to transfer money to person C.

You have to decide how many TS you transfer to person $\mathrm{C}$ through person B. You can transfer 0, $1000,2000, \ldots$ up to $15000 \mathrm{TS}$.

Please use the bag to count your notes in the white envelope and to place discreetly the TS you want to transfer in the brown envelope.

The amount of TS that you leave in the white envelope is for you to take home. Keep the white envelope for yourself. Leave the brown envelope in the bag.

An assistant will collect the bags containing the brown envelope and give them to another assistant who will bring the bags to the room of persons B. There, the person B you are matched with will receive your bag marked with the id number of your group and containing the brown envelope.

Then you will receive instructions for the next task to complete before being allowed to leave the room.

\section{If you are a person $B$}

You will receive from the person A you are matched with a bag marked with the id number of your group of three. This bag contains two envelopes, white and brown.

- The white envelope contains $5000 \mathrm{TS}$ for you to take home.

- The brown envelope contains the TS that the person A you are matched with wants you to transfer to the person $\mathrm{C}$ in your group. 
Please use the bag to count discreetly the notes in the white envelope and in the brown envelope.

After counting, you have to decide how many TS to leave in the brown envelope. You are not allowed to add any of your TS in the brown envelope. Keep the white envelope for yourself. Leave the brown envelope in the bag.

An assistant will collect the bags containing the brown envelope and give them to another assistant who will bring the bags to the room of persons $\mathrm{C}$. There, the person $\mathrm{C}$ you are matched with will receive the bag marked with the id number of your group and containing the brown envelope.

Then you will receive instructions for the next task to complete before being allowed to leave the room.

\section{If you are a person $\mathrm{C}$}

You will receive instructions for a task to complete.

Then, you will receive a bag marked with the id number of your group of three. This bag contains two envelopes, white and brown.

- $\quad$ The white envelope contains 2000 TS.

- The brown envelope contains the TS that the person B you are matched with transferred to you on behalf of person A. Person B cannot transfer any of his own TS to you.

The amount of TS in the white and the brown envelopes is for you to take home. Keep these envelopes for yourself. Leave the bag.

Then you will be allowed to leave the room.

\section{Information}

Person A does not know how many TS the person B has left in the brown envelope that was received by person C.

Person C does not know how many TS the person A has put in the brown envelope that was received by person B.

[This paragraph has been replaced with the following in the 1-Int-I treatment:

Person A does not know how many TS the person $B$ has left in the brown envelope that was received by person $C$. Person $C$ knows how many TS the person A has put in the brown envelope that was received by person B.]

If you have any question, please raise your hand and an experimenter will come to you and answer your questions in private.

From now until the end of the experiment, it is strictly forbidden to talk, otherwise you will be excluded from the session and earnings.

\section{Instructions for the 2-Int-NI treatment}

(The differences with the 2-Int-I treatment are indicated in italics)

We thank you for your participation in this experiment on decision-making. During this experiment, you will be able to earn Tanzanian Shillings (TS) in cash. Your decisions or responses to questions will be strictly anonymous and confidential. You will be identified only by an id code throughout the experiment.

In this experiment we randomly form groups of four people. Each group consists of one person A, one person B1, one person B2, and one person $\mathrm{C}$. The identity of the other group members will remain anonymous throughout the experiment.

After reading the instructions, each of you will be randomly assigned to one of four different rooms that correspond to the four different roles. Once in the room, all the participants in this room will be assigned the same role. This means that all the participants A will be in the same room; all the participants B1 will be in another room; all the participants B2 will be in a third room and all the participants $\mathrm{C}$ will be in a fourth room. Once in your room, you will learn your role and you will never meet again the participants in the other roles.

\section{The task}

At the beginning of the experiment in each group, person A receives 15000 TS. Person B1 and person B2 each receive 5000 TS. Person $C$ receives 2000 TS.

Person A has to decide how many TS to transfer to person C. Person A can choose any amount between 0 and 15 000 TS, as multiples of 1000 TS (either $0,1000,2000, \ldots, 15$ 000). 
If person $\mathrm{A}$ sends money to person $\mathrm{C}$, the transfer has to be done through two successive intermediaries, person $\mathrm{B} 1$ and person B2. The role of persons B1 and B2 is to transfer the money to person C. Persons B are not allowed to transfer their own TS to person $\mathrm{C}$.

Person $\mathrm{C}$ has no decision to make.

\section{If you are a person $A$}

You will receive a bag marked with the id number of your group of four. This bag contains two envelopes, white and brown.

- The white envelope contains $15000 \mathrm{TS}$.

- $\quad$ The brown envelope is empty and you can use it to transfer money to person C.

You have to decide how many TS you transfer to person $\mathrm{C}$ through person B. You can transfer $0,1000,2000, \ldots$ up to $15000 \mathrm{TS}$.

Please use the bag to count your notes in the white envelope and to place discreetly the TS you want to transfer in the brown envelope.

The amount of TS that you leave in the white envelope is for you to take home. Keep the white envelope for yourself. Leave the brown envelope in the bag.

An assistant will collect the bags containing the brown envelope and give them to another assistant who will bring the bags to the room of persons B1. There, the person B1 you are matched with will receive your bag marked with the id number of your group and containing the brown envelope.

Then you will receive instructions for the next task to complete before being allowed to leave the room.

\section{If you are a person $B 1$}

You will receive from the person A you are matched with a bag marked with the id number of your group of four. This bag contains two envelopes, white and brown.

- The white envelope contains 5000 TS for you to take home.

- The brown envelope contains the TS that the person A you are matched with wants you to transfer to the person $\mathrm{C}$ in your group through person $\mathrm{B} 2$.

Please use the bag to count discreetly the notes in the white envelope and in the brown envelope.

After counting, you have to decide how many TS to leave in the brown envelope. You are not allowed to add any of your TS in the brown envelope. Keep the white envelope for yourself. Leave the brown envelope in the bag. An assistant will collect the bags containing the brown envelope and give them to another assistant who will bring the bags to the room of persons B2. There, the person B2 you are matched with will receive the bag marked with the id number of your group and containing the brown envelope.

Then you will receive instructions for the next task to complete before being allowed to leave the room.

\section{If you are a person $B 2$}

You will receive from the person A and the person B1 you are matched with a bag marked with the id number of your group of four. This bag contains two envelopes, white and brown.

- $\quad$ The white envelope contains 5000 TS for you to take home.

- The brown envelope contains the TS that the person A you are matched with wants you to transfer to the person $\mathrm{C}$ in your group and that person $\mathrm{B} 1$ has left.

Please use the bag to count discreetly the notes in the white envelope and in the brown envelope.

After counting, you have to decide how many TS to leave in the brown envelope. You are not allowed to add any of your TS in the brown envelope. Keep the white envelope for yourself. Leave the brown envelope in the bag.

An assistant will collect the bags containing the brown envelope and give them to another assistant who will bring the bags to the room of persons $\mathrm{C}$. There, the person $\mathrm{C}$ you are matched with will receive the bag marked with the id number of your group and containing the brown envelope.

Then you will receive instructions for the next task to complete before being allowed to leave the room. 


\section{If you are a person $\mathrm{C}$}

You will receive instructions for a task to complete.

Then, you will receive a bag marked with the id number of your group of four. This bag contains two envelopes, white and brown.

- The white envelope contains $2000 \mathrm{TS}$.

- The brown envelope contains the TS that the person B1 and the person B2 you are matched with transferred to you on behalf of person A. Persons B1 and B2 cannot transfer any of their own TS to you.

The amount of TS in the white and the brown envelopes is for you to take home. Keep these envelopes for yourself. Leave the bag.

Then you will be allowed to leave the room.

Information

Person A does not know how many TS the person B1 and then the person B2 have left in the brown envelope that was received by person $\mathrm{C}$.

Person B2 does not know how many TS the person B1 received from person A.

Person C does not know how many TS the person A has put in the brown envelope that was received by person B1 and then by person B2.

[This paragraph has been replaced with the following in the 2-Int-I treatment:

Person A does not know how many TS the person B1 and then the person B2 have left in the brown envelope that was received by person $C$.

Person $B 2$ does not know how many TS the person $B 1$ received from person $A$.

Person $C$ knows how many TS the person A has put in the brown envelope that was received by person BI and then by person B2.]

If you have any question, please raise your hand and an experimenter will come to you and answer your questions in private. From now until the end of the experiment, it is strictly forbidden to talk, otherwise you will be excluded from the session and earnings.

\section{Final instructions common to all treatments}

(These instructions were distributed in rooms $A$ and $B$ after the bags have been collected. They were distributed in room $C$ before the bags were distributed)

Please fill out the questionnaire that has been distributed to you. We remind you that all your responses are anonymous. Do not forget to mention your experimental id number at the top of this questionnaire. You receive 2 000 TS for answering this questionnaire.

Finally, you have an opportunity to earn extra money by tossing the coin that has been put on your table.

You can toss the coin as many times as you like, but you have to report only the first toss. Please toss the coin as discreetly as possible.

- If the first toss of the coin shows Head, you earn 2000 TS that will be added to your other payoffs.

- If the first toss of the coin shows Tail, you earn nothing in this task.

Please report at the end of the questionnaire form the outcome of your first coin toss. 
Appendix 2. The experimental settings

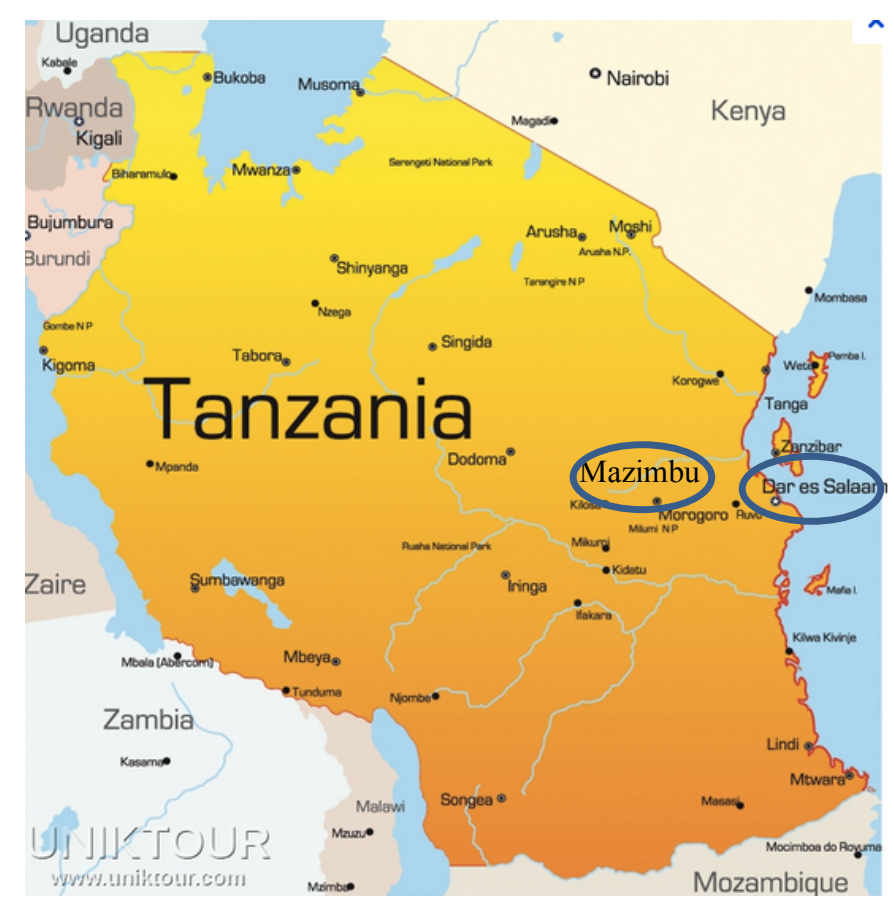

Experimental locations: Dar-es-Salaam and Mazimbu

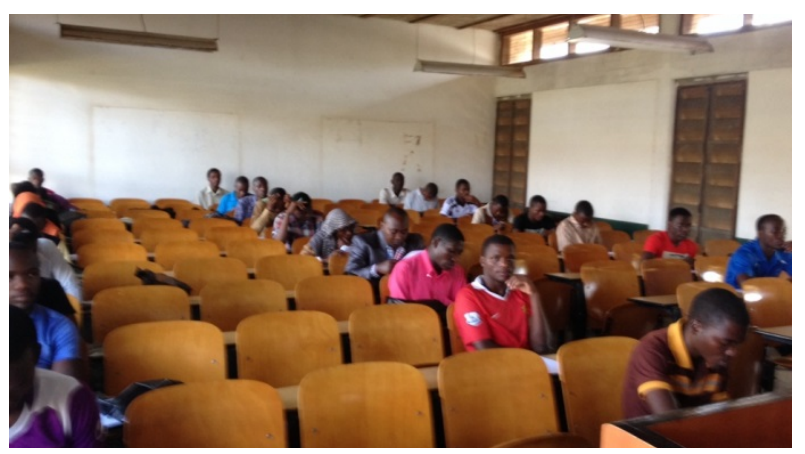

An experimental room

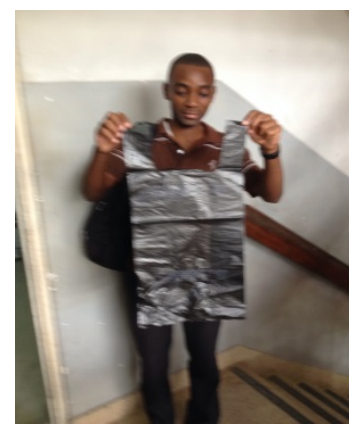

The bags used to transfer money and make decisions 


\section{Appendix 3. Tables}

Table A1. Determinants of the amount donated by the Senders (without socio-economic controls)

\begin{tabular}{lccc}
\hline $\begin{array}{l}\text { Dep. variable } \\
\text { Amount donated }\end{array}$ & $\begin{array}{c}\text { All } \\
\text { No intermediary }\end{array}$ & $\begin{array}{c}\text { Transparency } \\
(1)\end{array}$ & $\begin{array}{c}\text { No Transparency } \\
(3)\end{array}$ \\
\hline Ref. & Ref. & - \\
& & & Ref. \\
Long chain & $-572.078^{* *}$ & -473.956 & \\
& $(291.21)$ & $(321.60)$ & -130.456 \\
Transparency & $-883.642^{* * *}$ & $-955.153^{* * *}$ & $(370.93)$ \\
& $(281.88)$ & $(299.42)$ & - \\
Dar-es-Salaam & -292.041 & - & 178.317 \\
& $(278.90)$ & & $(371.44)$ \\
\hline Number of obs. & -122.376 & -268.389 & 120 \\
Left/right cens. obs. & $(221.46)$ & $(275.05)$ & $21 / 0$ \\
Log pseudo-likelih. & 360 & 240 & -967.135 \\
Prob $>$ Chi2 & -2899.500 & -1931.430 & 0.838 \\
Pseudo R & 0.047 & 0.017 & $<0.001$ \\
\hline
\end{tabular}

Notes: Table A1 reports marginal effects from Tobit models. Robust standard errors are in parentheses. Left censored observations correspond to a null transfer and right-censored observations to a transfer of the full endowment to the next player. $* * *$ and $*$ indicate significance at the 0.01 and 0.10 level, respectively.

Table A2. Determinants of the share of the amount received that is embezzled by an intermediary (without socio-demographic controls)

\begin{tabular}{|c|c|c|c|c|c|}
\hline $\begin{array}{l}\text { Dep. variable } \\
\text { Share embezzled }\end{array}$ & $\begin{array}{l}\text { All } \\
(1)\end{array}$ & $\begin{array}{l}\text { Excluding } 1^{\text {st }} \\
\text { intermediary } \\
\text { (2) }\end{array}$ & $\begin{array}{l}\text { Excluding } 2^{\text {nd }} \\
\text { intermediary } \\
\text { (3) }\end{array}$ & $\begin{array}{l}\text { Long chain } \\
\text { Transparency } \\
\text { (4) }\end{array}$ & $\begin{array}{l}\text { Long chain No } \\
\text { Transparency } \\
\text { (5) }\end{array}$ \\
\hline Short chain & Ref. & Ref. & Ref. & - & - \\
\hline Long chain & $\begin{array}{c}-0.025 * * \\
(0.011)\end{array}$ & $\begin{array}{l}-0.011 \\
(0.015)\end{array}$ & $\begin{array}{c}-0.040 * * * \\
(0.014)\end{array}$ & - & - \\
\hline Transparency & $\begin{array}{l}-0.014 \\
(0.010)\end{array}$ & $\begin{array}{c}-0.028^{* *} \\
(0.014)\end{array}$ & $\begin{array}{l}-0.009 \\
(0.013)\end{array}$ & - & - \\
\hline $\begin{array}{l}1^{\text {st }} \text { intermediary } \\
\text { Amount received } \\
\text { (rescaled) } \\
\text { Dar-es-Salaam }\end{array}$ & $\begin{array}{c}-0.004 * * \\
(0.002) \\
0.046 * * * \\
(0.012)\end{array}$ & $\begin{array}{c}-0.003 \\
(0.002) \\
0.064 * * * \\
(0.017)\end{array}$ & $\begin{array}{c}-0.005 * * \\
(0.002) \\
0.049 * * * \\
(0.015)\end{array}$ & $\begin{array}{c}-0.009 \\
(0.017) \\
-0.004 \\
(0.004) \\
0.011 \\
(0.019)\end{array}$ & $\begin{array}{c}-0.035^{*} \\
(0.019) \\
-0.004 * \\
(0.002) \\
0.058 * * * \\
(0.020)\end{array}$ \\
\hline Number of obs. & 264 & 164 & 190 & 90 & 84 \\
\hline Left/right cens. obs. & 91/87 & 49/61 & $66 / 57$ & $33 / 28$ & $34 / 28$ \\
\hline Log pseudo-likelih. & -276.497 & -166.289 & -197.079 & -97.292 & -82.958 \\
\hline Prob $>$ Chi 2 & $<0.001$ & $<0.001$ & $<0.001$ & 0.591 & 0.007 \\
\hline Pseudo $\mathrm{R}^{2}$ & 0.042 & 0.067 & 0.049 & 0.010 & 0.087 \\
\hline
\end{tabular}

Notes: Table A2 reports marginal effects from Tobit models. Robust standard errors clustered at the group level (since the two intermediaries are not independent) are in parentheses. The dependent variable takes values between 0 and 1. To facilitate the reading of the Table, the amount received from the previous player (either the donor or the first intermediary) has been rescaled (real amount divided by 1000), such that it can be read as the mean number of bills of TS 1000 received. Left censored observations correspond to no embezzlement and right-censored observations to full embezzlement. $* * *, *$, and $*$ indicate significance at the $0.01,0.05$, and 0.10 level, respectively. 
Table A3. Determinants of the share of the amount received that is embezzled by an intermediary

\begin{tabular}{lcccc}
\hline $\begin{array}{l}\text { Dep. variable } \\
\text { Share embezzled }\end{array}$ & $\begin{array}{c}\text { Short chain } \\
(1)\end{array}$ & $\begin{array}{c}\text { Short chain } \\
(2)\end{array}$ & $\begin{array}{c}\text { Long chain } \\
(3)\end{array}$ & $\begin{array}{c}\text { Long chain } \\
(4)\end{array}$ \\
\hline Transparency & -0.032 & $-0.050^{*}$ & -0.009 & -0.014 \\
& $(0.023)$ & $(0.027)$ & $(0.011)$ & $(0.012)$ \\
Amount received & -0.003 & -0.004 & $-0.004^{* *}$ & $-0.005^{* * *}$ \\
(rescaled) & $(0.004)$ & $(0.004)$ & $(0.002)$ & $(0.002)$ \\
Dar-es-Salaam & $0.087^{* * *}$ & $0.112^{* * *}$ & $0.032^{* * *}$ & $0.039^{* * *}$ \\
& $(0.027)$ & $(0.031)$ & $(0.012)$ & $(0.013)$ \\
Male & - & 0.041 & - & $0.045^{* * *}$ \\
& & $(0.031)$ & & $(0.015)$ \\
Age & - & -0.007 & - & -0.004 \\
& & $(0.005)$ & & $(0.003)$ \\
Married & - & $0.140^{* * *}$ & - & -0.026 \\
& & $(0.054)$ & & $(0.030)$ \\
Christian & - & -0.047 & -0.012 \\
& & $(0.037)$ & & $(0.014)$ \\
Religious practice & - & $-0.036^{* * *}$ & - & -0.001 \\
& & $(0.013)$ & & $(0.006)$ \\
\hline Number of obs. & 90 & 90 & 174 & 171 \\
Left/right cens. obs. & $24 / 31$ & $24 / 31$ & $67 / 56$ & $66 / 56$ \\
Log pseudo-likelih. & -88.017 & -79.795 & -185.075 & -174.040 \\
Prob>Chi2 & $<0.001$ & $<0.001$ & 0.008 & 0.001 \\
Pseudo R ${ }^{2}$ & 0.090 & 0.175 & 0.024 & 0.065 \\
\hline
\end{tabular}

Notes: Table A3 reports marginal effects from Tobit models. Robust standard errors clustered at the group level in long chains (since the two intermediaries are not independent) are in parentheses. The dependent variable takes values between 0 and 1. To facilitate the reading of the Table, the amount received from the previous player (either the donor or the first intermediary) has been rescaled (real amount divided by 1000), such that it can be read as the mean number of bills of TS 1000 received. Left censored observations correspond to no embezzlement and rightcensored observations to full embezzlement. 2 observations on religious practice are missing (one in 2-Int-I and one in 2-Int-NI) and one observation on gender is missing in 2-Int-I. ***, **, and * indicate significance at the 0.01 , 0.05 , and 0.10 level, respectively. 
Appendix 4. Figure A1. Mean percentage of the amount received that is embezzled, by category of amount received, treatment and rank in the transfer chain

Figure A1 displays the embezzlement percentage for three categories of amount received $(1000,2000$ and 3000,4000 and more), by treatment. This division is arbitrary but guarantees a sufficient number of observations in each cell.

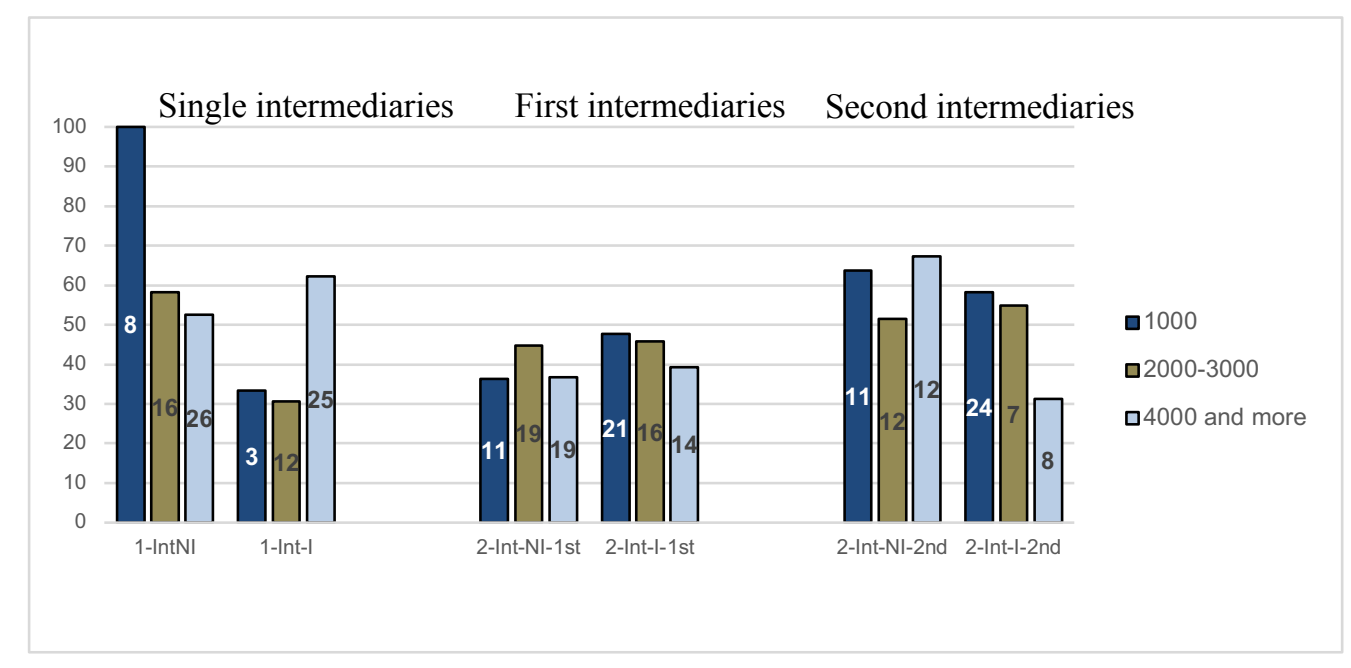

Notes: The number in each bar corresponds to the number of observations. The percentages are conditional on receiving from the previous player a positive amount to transfer. 